Article

\title{
Remote Sensing for Short-Term Economic Forecasts
}

\author{
Carsten Juergens ${ }^{1, *} \mathbb{0}$, Fabian M. Meyer-Heß ${ }^{1} \mathbb{D}$, Marcus Goebel ${ }^{1}$ and Torsten Schmidt ${ }^{2}$ \\ 1 Geomatics Group, Geography Department, Ruhr University Bochum, 44801 Bochum, Germany; \\ matthias.meyer@ruhr-uni-bochum.de (F.M.M.-H.); marcus.goebel@rub.de (M.G.) \\ 2 RWI-Leibniz-Institut für Wirtschaftsforschung e.V., 45128 Essen, Germany; torsten.schmidt@rwi-essen.de \\ * Correspondence: carsten.juergens@rub.de
}

Citation: Juergens, C.; Meyer-Heß,

F.M.; Goebel, M.; Schmidt, T. Remote Sensing for Short-Term Economic Forecasts. Sustainability 2021, 13, 9593 https://doi.org/10.3390/su13179593

Academic Editors: Samo Bobek, Simona Sternad Zabukovsek and Jarmila Zimmermannová

Received: 14 July 2021

Accepted: 23 August 2021

Published: 26 August 2021

Publisher's Note: MDPI stays neutral with regard to jurisdictional claims in published maps and institutional affiliations.

Copyright: (c) 2021 by the authors. Licensee MDPI, Basel, Switzerland. This article is an open access article distributed under the terms and conditions of the Creative Commons Attribution (CC BY) license (https:// creativecommons.org/licenses/by/ $4.0 /)$.

\begin{abstract}
Economic forecasts are an important instrument to judge the nation-wide economic situation. Such forecasts are mainly based on data from statistical offices. However, there is a time lag between the end of the reporting period and the release of the statistical data that arises for instance from the time needed to collect and process the data. To improve the forecasts by reducing the delay, it is of interest to find alternative data sources that provide information on economic activity without significant delays. Among others, satellite images are thought to assist here. This paper addresses the potential of earth observation imagery for short-term economic forecasts. The study is focused on the estimation of investments in the construction sector based on high resolution (HR) (10-20 m) and very high resolution (VHR) (0.3-0.5 m) images as well as on the estimation of investments in agricultural machinery based on orthophotos $(0.1 \mathrm{~m})$ simulating VHR satellite imagery. By applying machine learning it is possible to extract the objects of interest to a certain extent. For the detection of construction areas, VHR satellite images are much better suited than HR satellite images. VHR satellite images with a ground resolution of $30-50 \mathrm{~cm}$ are able to identify agricultural machinery. These results are promising and provide new and unconventional input for economic forecasting models.
\end{abstract}

Keywords: economic forecast; earth observation; machine learning; Sentinel-2; WorldView; postclassification comparison; template matching; change detection

\section{Introduction}

Economic investment is a key factor for a country's economic development both in the long-term and in the short-term. In many cases, an appropriate development of public infrastructure is an important prerequisite for private investments and thus sustainable economic growth. In this context, Alaloul et al. (2021) [1] highlight the importance of a country's construction sector for the development because it is closely intertwined with other sectors of the economy. However, private investment is highly volatile in the short term. Housing investments in particular exhibit pronounced boom bust cycles (Agnello and Schuknecht 2011) [2]. The financial crisis of the years 2008 and 2009 is an example that these housing cycles might have strong effects on the financial sector and are therefore a threat to financial sector stability (Lee et al., 2021) [3]. On the other hand, due to several macroprudential policy tools related to the housing market it has the capacity to stabilize the financial sector and promote sustainability of the economic development (CarrascoGallego 2021) [4].

For this reason, the macroeconomic analyses and forecasts of governments at the federal and the state level, central banks, and international organizations like the European Commission also include, among other things, analysis and forecast of investment and, in particular, construction investment. Therefore, forecasts are built bottom up starting with the most important components of gross domestic product (GDP), like consumption, investment in equipment and construction, as well as external trade. This allows in depth analysis of the different economic activities within the economy. For this reason, the most 
important source for these forecasts is the system of national accounts. In Germany, detailed quarterly data for the whole country from the system of national accounts is published six weeks after the end of the quarter. At the state level, GDP data are available at an annual frequency and published three months after the end of the year. Since the actual needs for this data require quicker forecasting reports, forecasters are looking for unconventional data sources that are available independently from those official statistics and which are able to support quicker but reliable forecasts (e.g., Donaldson and Storeygard 2016 [5], Ademmer et al., 2021 [6], Blagov et al., 2021 [7]).

In particular, investments in construction and in machinery play an important role in the forecasting process as these variables indicate short-run changes in economic activity quite early. The financial crisis of the years 2008 and 2009 is popular evidence that the housing sector often drives the business cycle. From this perspective, it is very interesting that buildings could be identified in satellite images from space. This opens up the possibility that earth observation satellite images could provide information that is able to improve economic forecasts (Blagov et al., 2021 [7]).

Early studies with macro-economic focus used night light image data to estimate the state of economic development (e.g., Henderson et al., 2012 [8]). Usually, GDP per capita is used as a measure for this purpose but, in developing and emerging countries, reliable data are not always available to calculate GDP per capita. According to Small et al. (2011) [9], DMSP (Defense Meteorological Satellite Program) data can be used globally to analyze long-run economic development. The advantage of such data is the global availability in identical quality and the long time series of data over more than 20 years. For macroeconomic analysis in well-developed countries, their benefit is discussed controversially. Nordhaus and Chen (2015) [10], Addison and Stewart (2015) [11], and Leßmann et al. (2015) [12] are rather pessimistic on the use of DMSP data for income forecasts. Another example is Faisal and Shaker 2014 [13], who successfully examine the relationship between built-up areas derived from remote sensing and socio-economic parameters such as GDP in selected Canadian cities. However, this study uses Landsat satellite images with a relatively coarse resolution and utilizes a rather simple classification approach based on two indices.

In addition, other studies were looking for further applications of remote sensing image data for economic analysis like investments in other goods. Very high resolution (VHR) images seem to allow the identification of cars on parking lots (e.g., Spaceknow [14], Schartner 2018 [15]). This information could be used as an indicator of the volume of sales in the neighboring shops and therefore could improve short-term forecasts of private consumption. However, the application of earth observation data for the analysis of shortterm economic activity is in an early stage of its development. Feasibility studies like the "smart business cycle statistics" project from EUROSTAT propose positive evaluations but still there is a need for specific case studies to judge the effects of integrating information from earth observation satellites into economic models. Mostly related to our study are empirical analyses of land use change by using remote sensing data. Riao et al. (2020) [16] and Wang et al. (2020) [17] analyzed the urbanization process in different regions in China. The studies prove the extensive conversion of arable land into building land.

Various earth observation systems have already been available for decades and offer satellite images with different spatial and temporal resolutions. However, comprehensive free data in a high resolution (HR) of up to $10 \mathrm{~m}$ have only been available since the launch of modern non-commercial sensors such as the European Space Agency's Sentinel satellites of the Copernicus program in 2014. Images with very high resolutions (VHR) are acquired from commercial satellites such as WorldView $(0.3-0.5 \mathrm{~m})$.

Corresponding to the variety of different earth observation satellites with their specific characteristics, research studies developed many different strategies to extract information from the imagery. Early methods were based on pixel-based classification strategies that later were complemented by object-based classification approaches (e.g., Myint et al., 2011 [18], Blaschke et al., 2008 [19]). These were then complemented by a huge 
variety of machine learning approaches to use other image features during the classification stage (e.g., Mao et al., 2020 [20]).

Since satellite images can be acquired with high temporal frequency, they seem to be well suited to support a modified reporting strategy by identifying new construction sites and new buildings and therefore construction investments by comparison with earlier situations. Xi et al. (2019) [21] as well as Pesaresi et al. (2016) [22] investigate the use of optical Sentinel-2 data for built-up area detection. Once buildings are detected, it is necessary to evaluate which buildings are new compared to an earlier point in time. Here, specific change detection approaches are necessary (e.g., Radke et al., 2005 [23], Olteanu-Raimond et al., 2020 [24], Henits et al., 2016 [25]). Juergens and Meyer-Heß (2021) [26] worked with finer spatial resolution and reported on their findings related to construction areas based on mono-temporal VHR satellite images and combined change detection analysis.

Similar to that is the identification of new agricultural machinery on outdoor parking lots, where those goods are waiting to be delivered to the customer. A probable solution could be the detection of the machinery's pattern within an image using Template Matching as described by (Jasvilis et al., 2016 [27]) for other complex structures such as oil palms or pavement markings. By assessing the outdoor "storage" this way using VHR satellite images in certain intervals, the estimation of the full number of produced land machines seems feasible. For instance, Rosenski and Schartner (2018) [28] report on such possible applications of VHR satellite images for economic statistics. Further related to this work is research by Zambanini et al., 2020 [29], who use VHR stereo satellite imagery for the development of parking space availability models, as well as Tang et al., 2017 [30], who optimize Faster R-CNN for general methodological purposes. However, this study aims at national forecasts. Thus, the short-term detection of construction sites and vehicles with as inexpensive data as possible is too focused and does not allow the use of stereo imagery or LiDAR-derived 3D-models as well as extensive training of machine learning approaches.

Since there is a need and great potential in the HR and VHR image domain for economic applications, this study concentrates on the estimation of investments in the construction sector based on HR and VHR images and on the estimation of investments in agricultural machinery based on orthophotos simulating VHR satellite imagery. Overall, this paper investigates the potential of earth observation imagery for short-term economic forecasting.

\section{Materials and Methods}

The basic objective is to find out if optical remote sensing data are able to improve short-term economic forecasts. These forecasts are typically produced by using time series models based on economic data. One target variable is construction investments, which are published quarterly. In Germany, data for construction investments are published by the Federal Statistical Office six weeks after the end of the quarter of interest. Another target variable is the investment in machinery.

Variables that are commonly used for forecasting construction investments are either general measures of economic activity like GDP, the unemployment rate (Alaloul et al., 2021 [1]; Ng et al., 2011 [31]), or variables that are related to the demand or supply side of the housing market (Demers 2005 [32]; Lunsford 2015 [33]). Demers (2005) [32] uses the price of housing accommodation, the share of the 25- to 44-year-old population, wealth of households, and the interest rate as explanatory variables in the forecast equation. However, some of these variables are published with a lag and, even more importantly, none of these variables is directly related to construction investments. To reduce this problem, an alternative approach includes leading indicators in the forecasting equation that are directly related to the construction sector. Lunsford (2015) [33] uses building permits and housing starts that are published monthly. In Germany, only building permits are available on a monthly basis at the federal level. Unfortunately, they are published with a delay of six weeks. At the state level, building 
permits are published quarterly with a delay of six weeks. Another important variable is the number of workers in the construction sector. Forecast evaluation studies (e.g., Aye et al., 2016 [34]) find that specific housing market variables are able to improve the forecasting performance. From this perspective, the advantages of satellite image data are that it measures construction activity directly and the data provide information on the regional distribution of construction activity. This information must be converted into quantitative time series data, preferably with a monthly or quarterly frequency.

To analyze the general information content of satellite image data, open satellite image data of the Sentinel-2 satellites are investigated first. The aim is to construct a quantitative measure for construction activities in a specific area. A possible measure is the number of construction sites or the size of the areas of these construction sites. In case these data from the satellite images is too coarse, one could add commercial VHR data instead, to reach higher accuracies.

For the methodological approaches one followed three ideas:

1. Exploit freely available HR Sentinel-2 data to detect construction areas and new buildings by using the spectral bands with $10 \mathrm{~m}$ and $20 \mathrm{~m}$ geometric resolution (Section 2.1.1). Based on the twin constellation of Sentinel-2A and Sentinel-2B it is possible to get their imagery every five days.

2. Extract construction areas with high precision from commercial VHR images of the WorldView satellite family with $0.3 \mathrm{~m}-0.5 \mathrm{~m}$ and find out which benefits could result from using the higher geometric resolution (Section 2.1.2). Based on the orbital characteristics and the pointing capabilities of the WorldView satellites, it is possible to get their imagery every $1-5$ days.

3. Perform a feasibility study on the possible extraction of agricultural machinery in different image resolutions. Due to availability and practical reasons, the use of VHR satellite images will be simulated with orthophotos. The original resolution of $0.1 \mathrm{~m}$ will be reduced to $0.3 \mathrm{~m}, 0.5 \mathrm{~m}$, and $1 \mathrm{~m}$ to find the minimal resolution that is needed for successful detections of agricultural machinery. This could then ease the choice of suitable satellite imagery to perform the same task on larger scales (Section 2.2).

\subsection{Detection of Construction Sites}

To evaluate the usability of HR and VHR earth observation data to identify and quantify construction activities, the German capital Berlin is selected as it must publish national accounts data including construction investments as a federal state. This investigation is based on freely available HR Sentinel-2 images and on commercial VHR images from the family of WorldView (WV) satellites.

Each scene is classified using object-based image analysis (OBIA) and a kNN (k-nearest neighbors) machine learning classifier as this approach visually worked best among the other machine learning techniques such as Support Vector Machine or Random Forest with the given data. The algorithm utilizes previously learned properties such as spectral signatures for different land cover classes and assigns unknown image objects accordingly. To train the classifier, samples are collected for each scene individually to gather representative surface information for each land cover category. Basically, the mono-temporal classification results for all individual scenes are then used to refine the result with GISbased analysis.

Two reference datasets are consulted for evaluation of built-up structures: The first one is the Imperviousness Classified Change (IMCC) 2015-2018 dataset, that contains changes of sealed surfaces from 2015 to 2018 with a resolution of $20 \mathrm{~m}$. It was produced as part of the Copernicus program and is a continuation of a time series going back to 2006, which is derived from HR satellite data (including Sentinel-2) and other data sources (Copernicus [35]).

The second dataset, Land Cover DE of the German Aerospace Center (DLR), is based on Sentinel-2 scenes from June 2015 to April 2017 and includes a multi-temporal land cover classification with a geometric resolution of $10 \mathrm{~m}$. It covers the whole of Germany 
and is subdivided into artificial surfaces (built-up areas), bare soil, water, and vegetation. The latter also includes a temporal component and is further subdivided into high/low and seasonal/permanent vegetation. In addition to the satellite spectral channels, a number of indices are used: Normalized Difference Vegetation Index (NDVI), Normalized Difference Water Index (NDWI), and Normalized Difference Built-Up Index (NDBI). Classification is performed using a Random Forest machine learning approach, taking additional information on sealing into account (DLR 2020 [36], Weigand et al., 2020 [37]).

\subsubsection{Sentinel-2 HR Image Analysis for the Detection of Construction Areas and New Buildings}

For the time period 2015-2020, available cloud-free Sentinel-2 scenes for the city of Berlin are downloaded. Altogether, the 20 scenes listed in Table 1 have good quality. It becomes clear that cloud-free images are less frequent in the second half of the year because the weather conditions in Germany's climate region do not allow more cloud-free image acquisition days in the respective seasons. This makes it more difficult to create a reliable indicator on a quarterly basis since the number of images differ between quarters, however statistical forecasts are traditionally based on observations at regular intervals. The Sentinel-2 images cover the area shown in Figure 1. Only the far eastern part is not covered, but the forest dominated area is of low interest for the detection of new buildings and construction areas. Therefore, this small missing area is neglected.

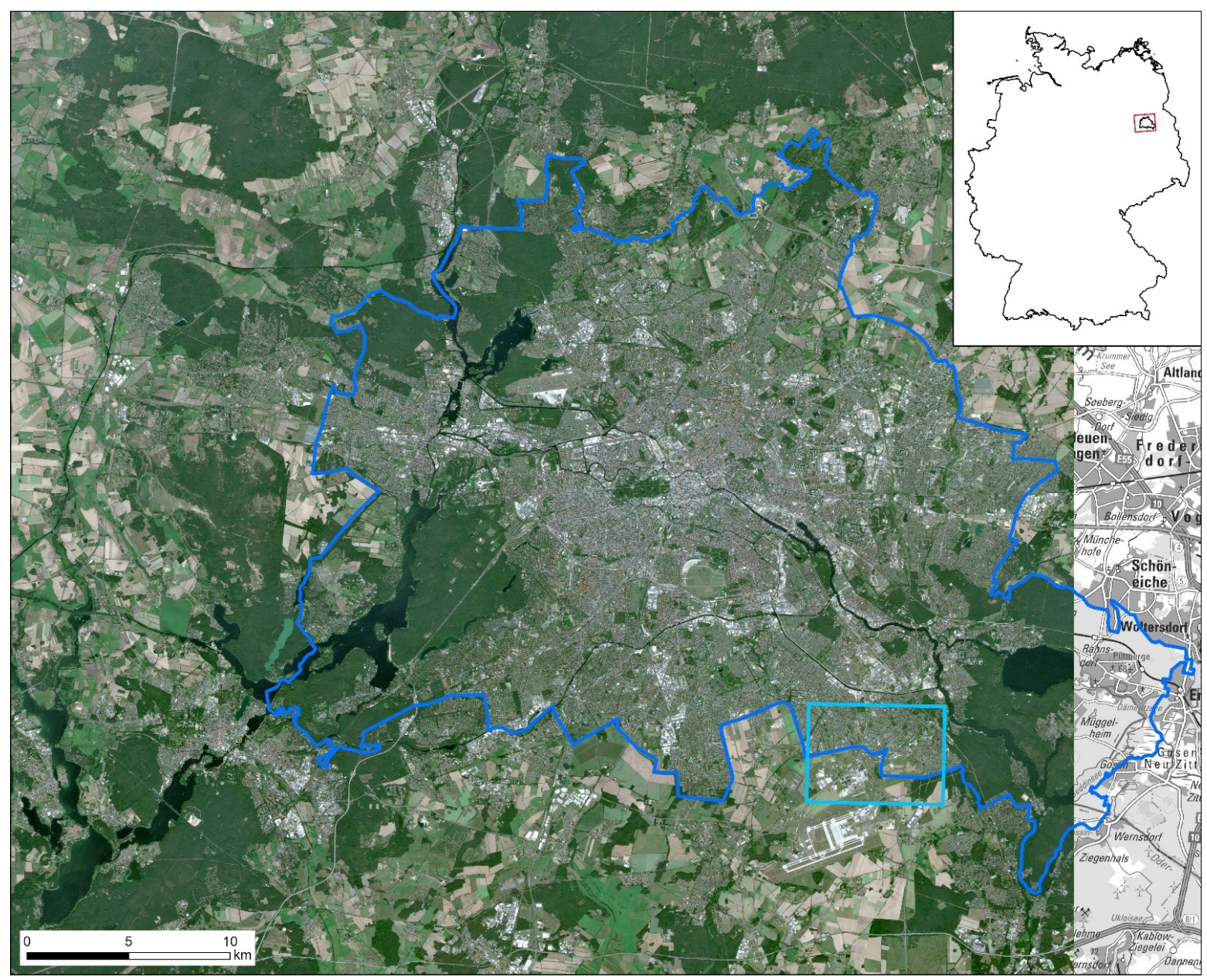

Figure 1. Study areas of the Sentinel-2 classification (image border) and of the WorldView classification (light blue) in comparison to the administrative boundary of Berlin (dark blue). Image source: natural color Sentinel-2 image of 27 August 2016, Copernicus Sentinel data 2016 (accessed on 26 August 2020) [38], background topographic map and overview: GeoBasis-DE/BKG 2021, http:/ / www.govdata.de/dl-de/ zero-2-0 (accessed on 5 June 2021) [39]. 
Table 1. Acquisition dates of cloud-free Sentinel-2 scenes for Berlin (2015-2020).

\begin{tabular}{|c|c|c|c|c|c|c|c|c|c|c|c|c|}
\hline & Jan & Feb & Mar & Apr & May & Jun & Jul & Aug & Sep & Oct & Nov & Dec \\
\hline 2015 & & & & & & & 4 & & & & & 24 \\
\hline 2016 & & & & 2 & & & & 27 & & & & \\
\hline 2017 & & 13 & & & 27 & & & & & 16 & & \\
\hline 2018 & & 8 & & & 7 & & & 7 & & & 28 & \\
\hline 2019 & & 16 & & 19 & & 13 & & 25 & & & & 10 \\
\hline 2020 & & 8 & & 6 & & 2 & & 16 & & & & \\
\hline
\end{tabular}

In this study, images of the past (2015-2020) are used to find an extraction methodology for new buildings and construction areas. Since some of the new objects (e.g., construction areas) can only be identified (to be buildings) after completion, one is dependent on images showing the final stage of a construction process. A simple indicator for construction activity within a region would be the number of construction completions between two observations. Even better would be an indicator based on information about the build-up areas. To comprise these future stages of development, one needs historical images for verification. Once the methodology works properly, it is believed that it can be applied on images without knowing the final stage beforehand.

All 20 scenes are classified according to the land cover nomenclature listed in Table 2. The nomenclature assumes that these classes are relevant and that construction activities could be characterized by bare soil without vegetation (e.g., construction sites) or by sealed surfaces consisting of artificial materials (e.g., concrete, roof tiles, etc.).

Table 2. Classification nomenclature for Sentinel-2 land cover classifications.

\begin{tabular}{cc}
\hline Color & Class Name \\
\hline & Bare Soil \\
& Vegetation \\
& Sealed surface \\
& Water \\
\hline
\end{tabular}

The idea behind the classification strategy is that each scene is classified independently, so that changes will turnout in the following image(s). Afterwards, a change detection approach based upon a post-classification comparison was performed.

For the classification approach, between 600 and 900 representative samples per scene for all different land cover types to cover all their different spectral appearances are defined manually. Different object features (spectral values, indices, and color space transformation) are used to feed the classifier (Table 3).

Table 3. Object features used for the Sentinel-2 land cover classifications.

\begin{tabular}{|c|c|c|}
\hline Feature Group & Band/Attribute & Based on ... \\
\hline Spectral & $\begin{array}{c}\text { B02 (blue, } 10 \mathrm{~m}) \\
\text { B03 (green, } 10 \mathrm{~m}) \\
\text { B04 (red, } 10 \mathrm{~m}) \\
\text { B08 (near infrared, } 10 \mathrm{~m}) \\
\text { B8A (red edge, } 20 \mathrm{~m}) \\
\text { B11 (shortwave infrared, } 20 \mathrm{~m}) \\
\text { B12 (shortwave infrared, } 20 \mathrm{~m} \text { ) }\end{array}$ & $\begin{array}{c}\text { means, } \\
\text { standard deviations, } \\
\text { maximum differences }\end{array}$ \\
\hline Indices & $\begin{array}{l}\text { NDVI } \\
\text { NDVIre } \\
\text { NDBI }\end{array}$ & $\begin{array}{c}(\mathrm{B} 08-\mathrm{B} 04) /(\mathrm{B} 08+\mathrm{B} 04) \\
(\mathrm{B} 8 \mathrm{~A}-\mathrm{B} 04) /(\mathrm{B} 8 \mathrm{~A}+\mathrm{B} 04) \\
(\mathrm{B} 11-\mathrm{B} 08) /(\mathrm{B} 11+\mathrm{B} 08)\end{array}$ \\
\hline IHS-Transformation & Intensity, Hue, Saturation & B02, B03, B04 \\
\hline
\end{tabular}

The high number and spectral resolution of the spectral bands of Sentinel-2 allows one to calculate a number of different indices (e.g., Normalized Difference Vegetation 
Index (NDVI), NDVIre (NDVI Red Edge), Normalized Difference Built-Up Index (NDBI), Built Up Index (BU), Urban Index (UI), etc.) and color transformations like IntensityHue-Saturation transformation (IHS-transformation), and also offers a good chance for simple spectral based classification. According to Jungnickl and Bill (2017) [40] as well as Ettehadi Osgouei et al. (2019) [41], one has to be careful with those "building indices" regarding seasonality effects. Here, the criteria to be used for the classifier as mentioned above are determined as explorative.

2.1.2. WorldView VHR Image Analysis for the Detection of Construction Areas and New Buildings

To investigate the benefits of higher spatial resolution, six commercial cloud-free pan-sharpened WorldView satellite images were ordered. Depending on the satellite, the spatial resolution is between $30 \mathrm{~cm}$ and $50 \mathrm{~cm}$ (Table 4). Due to this very high spatial resolution, the extraction of construction areas is especially in the focus here. To judge the suitability, one selected a test area $\left(\mathrm{ca} .30 \mathrm{~km}^{2}\right)$ at the southern edge of Berlin.

Table 4. Acquisition dates of cloud-free WorldView scenes.

\begin{tabular}{ccccccc}
\hline & $\mathbf{2 0 1 5 - 0 4 - 2 5}$ & $\mathbf{2 0 1 6 - 1 1 - 2 0}$ & $\mathbf{2 0 1 7 - 0 5 - 2 9}$ & $\mathbf{2 0 1 8 - 0 4 - 2 9}$ & $\mathbf{2 0 1 9 - 1 0 - 3 0}$ & 2020-08-08 \\
\hline Satellite & WV-3 & WV-3 & WV-4 & WV-3 & WV-2 & WV-2 \\
Resolution & $0.3 \mathrm{~m}$ & $0.3 \mathrm{~m}$ & $0.3 \mathrm{~m}$ & $0.3 \mathrm{~m}$ & $0.5 \mathrm{~m}$ & $0.4 \mathrm{~m}$ \\
\hline
\end{tabular}

Again, for the VHR images, this study uses images of the past (2015-2020) to find an extraction methodology for construction areas. The number of construction sites or the sum of the built-up area are simple indicators for construction activity within a given time-period. The logic is the same as with the Sentinel-2 images. Once the developed methodology works, it can be applied on further images without knowing the final stage beforehand. To get reliable information about construction activity within this area it would be ideal to get images at a quarterly frequency. Due to the climatic conditions in central Europe, clouds often obscure the satellite images. This causes an uneven distribution of cloud-free images, time-wise.

As construction areas are spectrally different from other land cover types, a land cover classification could be an efficient way to identify construction activities as well as new buildings. Prepared by an image segmentation, a K-nearest neighbor classification is applied, based on approximately 38,000 samples per image collected on a $4 \mathrm{~m}$ grid beforehand. Those samples are representative for each land cover class (Table 5). The object features listed in Table 6 are used to train the classifier.

Table 5. Classification nomenclature for WorldView land cover classifications.

\begin{tabular}{ccc}
\hline Color & Class & Group \\
\hline & Bare soil & unsealed \\
\hline & Vegetation & \\
\hline Construction & sealed \\
\hline & Industry & \\
\hline
\end{tabular}


Table 6. Object features used for the WorldView land cover classifications.

\begin{tabular}{ccc}
\hline Feature Group & Band/Attribute & Based on ... \\
\hline Spectral & Blue & Means, \\
& $\begin{array}{c}\text { Green } \\
\text { Red } \\
\text { Infrared }\end{array}$ & $\begin{array}{c}\text { standard deviations, } \\
\text { maximum differences }\end{array}$ \\
\hline Indices & NDVI & \\
\hline IHS-Transformation & Saturation, intensity & Red, green, blue \\
\hline
\end{tabular}

Per satellite scene, a mono-temporal classification is performed and the result is then used to refine it with GIS-based analysis.

The first attempt is to analyze the "classification pattern". It is based on the observation that construction areas are composed of many small objects of different materials. This could lead to neighboring areas classified to different land cover classes. To identify the class composition pattern, eight test sites are used, each for known residential, industrial, and construction areas. Inside each area, the class compositions and their frequency are analyzed. It is hoped that characteristic patterns for those three land cover types could be identified.

Since for each of the six image acquisition dates one classification result will be available, it is possible to consider a post-classification comparison based on more than one classification result. This time series constellation is an option to retrace the construction activities. The retrospective tracking of land cover changes can then help to understand the construction activity and use observed multi-temporal results for forecasting. Table 7 lists three possible approaches to identify new buildings and construction areas.

Table 7. Multi-temporal post-classification approaches for construction area identification.

\begin{tabular}{|c|c|c|c|c|c|c|}
\hline \multirow{7}{*}{ A } & \multicolumn{6}{|c|}{ New permanent sealing without visible construction sites } \\
\hline & 2015 & 2016 & 2017 & 2018 & 2019 & 2020 \\
\hline & unseale & sealed & & & & \\
\hline & & unsealed & sealed & & & \\
\hline & & & unsealed & sealed & & \\
\hline & & & & unsealed & sealed & \\
\hline & & & & & unsealed & sealed \\
\hline \multirow{6}{*}{ B } & \multicolumn{6}{|c|}{ Construction area on previously unsealed surfaces with subsequent sealing } \\
\hline & 2015 & 2016 & 2017 & 2018 & 2019 & 2020 \\
\hline & unseale & construction & sealed & & & \\
\hline & & unsealed & construction & sealed & & \\
\hline & & & unsealed & construction & sealed & \\
\hline & & & & unsealed & construction & sealed \\
\hline \multirow{5}{*}{$\mathrm{C}$} & \multicolumn{6}{|c|}{ Biennial construction areas with subsequent sealing } \\
\hline & 2015 & 2016 & 2017 & 2018 & 2019 & 2020 \\
\hline & \multirow[t]{3}{*}{ constru } & tion & & & & \\
\hline & & cons & ction & & & \\
\hline & & & cons & $\begin{array}{r}\text { se } \\
\text { cons }\end{array}$ & $\begin{array}{l}\text { d } \\
\text { ction }\end{array}$ & ed \\
\hline
\end{tabular}

Unsealed corresponds to the classes Bare Soil and Vegetation (Table 5); sealed corresponds to the classes Industry, Residential, and Other artificial (Table 5).

The first approach (A) does not identify a construction area between two image acquisitions, since in the first image there is no construction visible, but only the "normal" land cover. In the second image, the construction activity is already completed and new buildings can be observed. This could happen, if the time interval between the two cloud-free images is too large to identify construction activities in-between. 
Approach B is applicable when three stages can be identified. Beginning with no construction activity ("unsealed normal land cover"), followed by, secondly, a construction activity, and in the third image the stage of completed buildings.

The third approach $(\mathrm{C})$ is useful for construction areas that exist in two temporally adjacent images. In the third image the construction is completed.

\subsection{Detection of Machinery}

Besides investments in buildings, one is interested in investments in machinery. One significant type that can be observed from space is agricultural machinery which is typically parked on outdoor parking lots after completion. Since it is unclear if identification and counting of agricultural machinery is possible with VHR satellite images, an experiment with degraded aerial RGBI-ortho-images was designed. The ortho-images themselves are not available world-wide and have an uncertain temporal resolution, thus it is not considered for routine economic forecasts.

For the detection of vehicles or agricultural machinery, a parking lot of an important manufacturer in Harsewinkel, Germany, was chosen. For this area, a digital orthophoto with a spatial resolution of $10 \mathrm{~cm}$ was acquired. To use such images to judge the usability of agricultural machinery in VHR satellite images, the spatial resolution was degraded to $30 \mathrm{~cm}, 50 \mathrm{~cm}$, and $1 \mathrm{~m}$, which corresponds to most VHR satellites.

The detection of agricultural machinery or vehicles cannot be performed solely upon local spectral image properties to be reliable. Much more promising is the analysis of spatial patterns in an image's grey value matrix. This can be performed by identifying objects via template matching. The principle is based on the comparison between a given sample or template of the desired object and the image content. A template is moved across the image to identify fitting objects within the image. The fit is calculated by a correlation coefficient and the result is stored in a separate image. Locations with correlation values above a given threshold are assumed to be successful matches of the sought object (Figure 2).
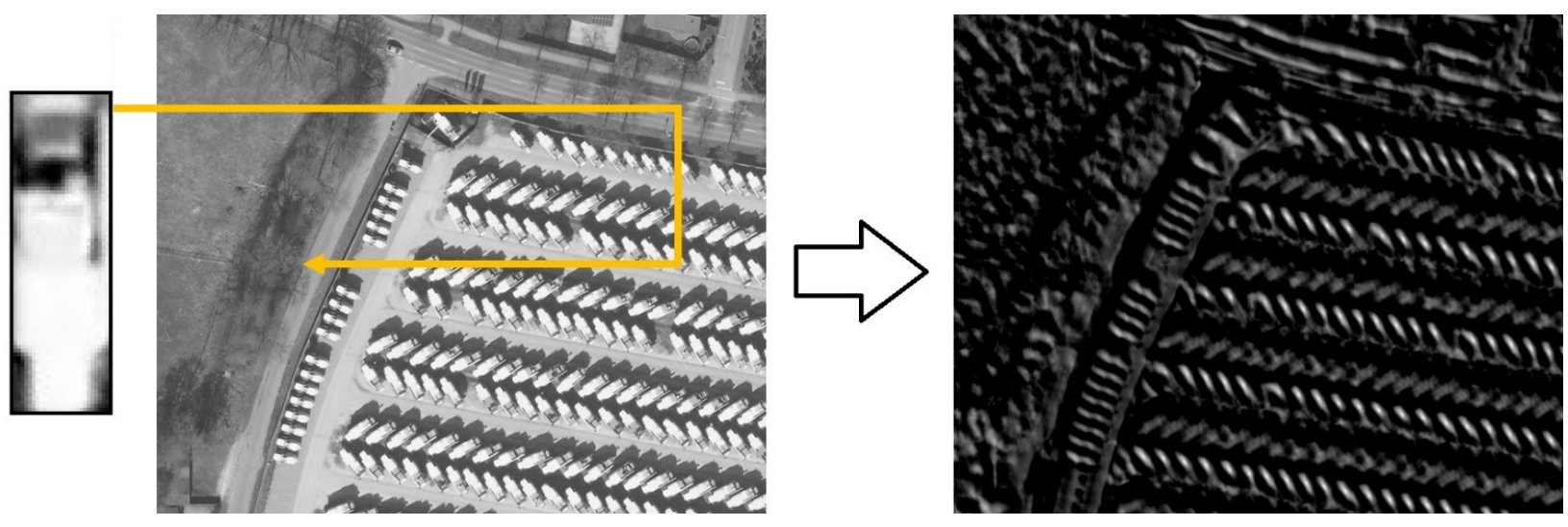

Figure 2. Principle of Template Matching. The template is moved across the orthophoto to produce an output image. The brighter a pixel, the higher correlation at the position. Orthophoto from 27 March 2017, image source: Land NRW, http:/ / www.govdata.de/dl-de/zero-2-0 (accessed on 5 June 2021) [42].

Template Matching is performed using eCognition. Templates are generated by measuring and fusing multiple example objects (Figure 3) to take different lighting conditions and vehicle configurations into account. These are then scaled and rotated during execution to detect vehicles in different orientations and sizes. 


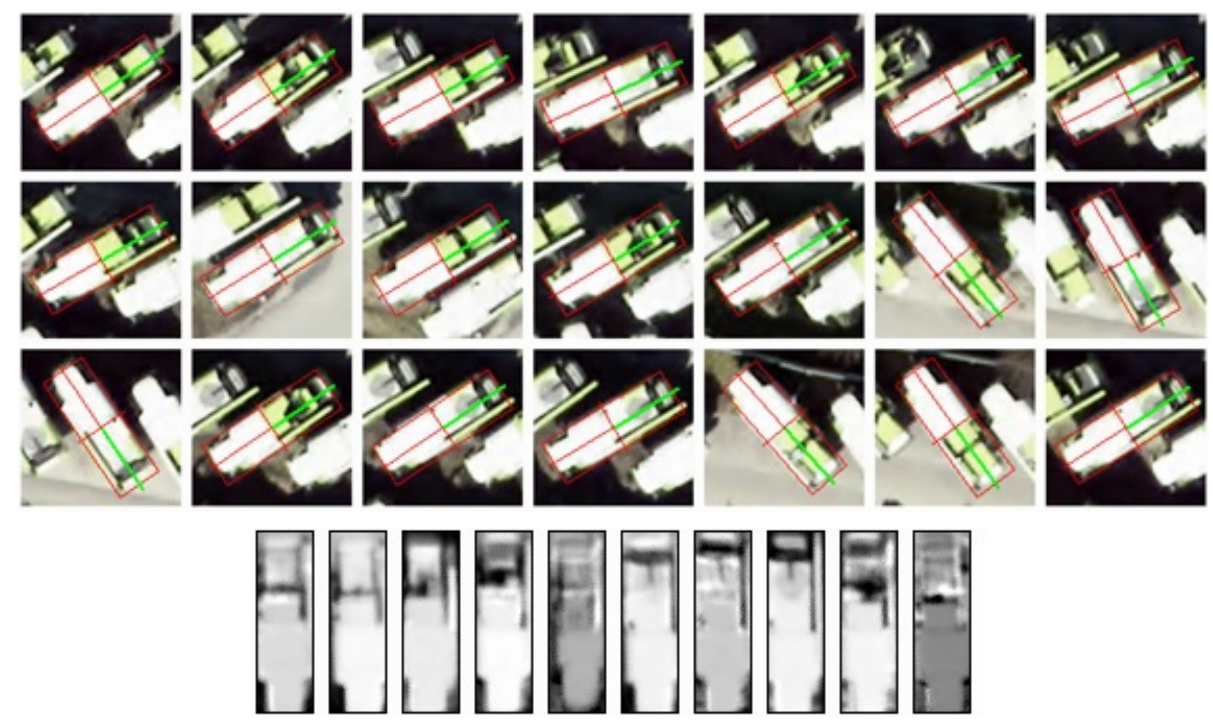

Figure 3. Generation of 10 templates (bottom) from image samples (top). Image source: Land NRW, http:/ / www.govdata.de/dl-de/zero-2-0 (accessed on 5 June 2021) [42].

To be able to judge the result, a reference data set is prepared manually. In the original ortho-image (27 March 2017) of the factory in Harsewinkel, all land machines are counted and transformed into a reference data set with 744 vehicles (Figure 4). This is later used to evaluate the results of the template matching based on different spatial resolutions. The template matching is applied to identify field choppers and combine harvesters with slightly varying configurations.

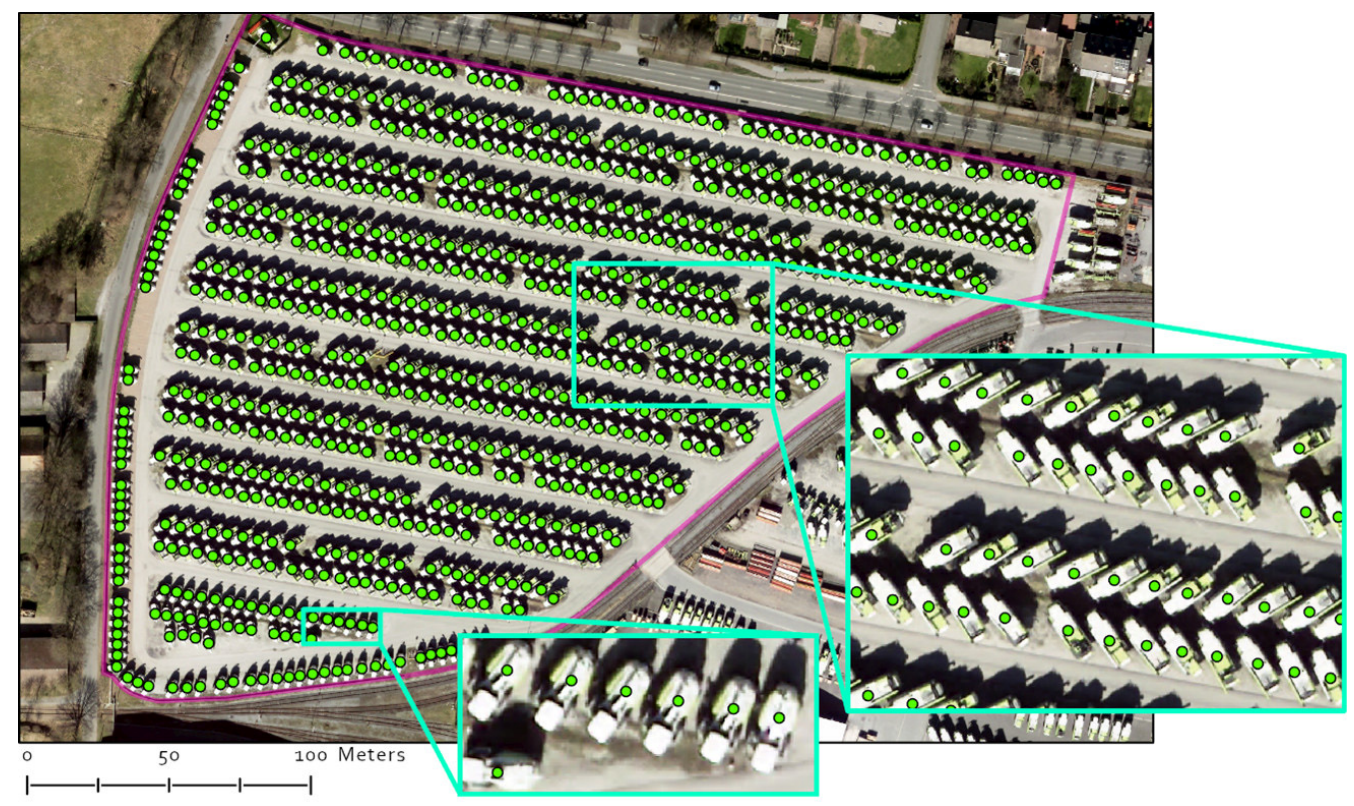

Figure 4. Parking lot with 744 highlighted agricultural vehicles of an important manufacturer in Harsewinkel, Germany. Orthophoto from 27 March 2017, image source: Land NRW, http: / /www. govdata.de/dl-de/zero-2-0 (accessed on 5 June 2021) [42].

\section{Results}

3.1. Results of the Sentinel-2 Classification

Figure 5 exemplarily shows the classification result of the Sentinel-2 scene of 16 October 2017. The different natural land cover classes and newly sealed areas can be clearly identified in the complete scene as well as in the enlarged area. 


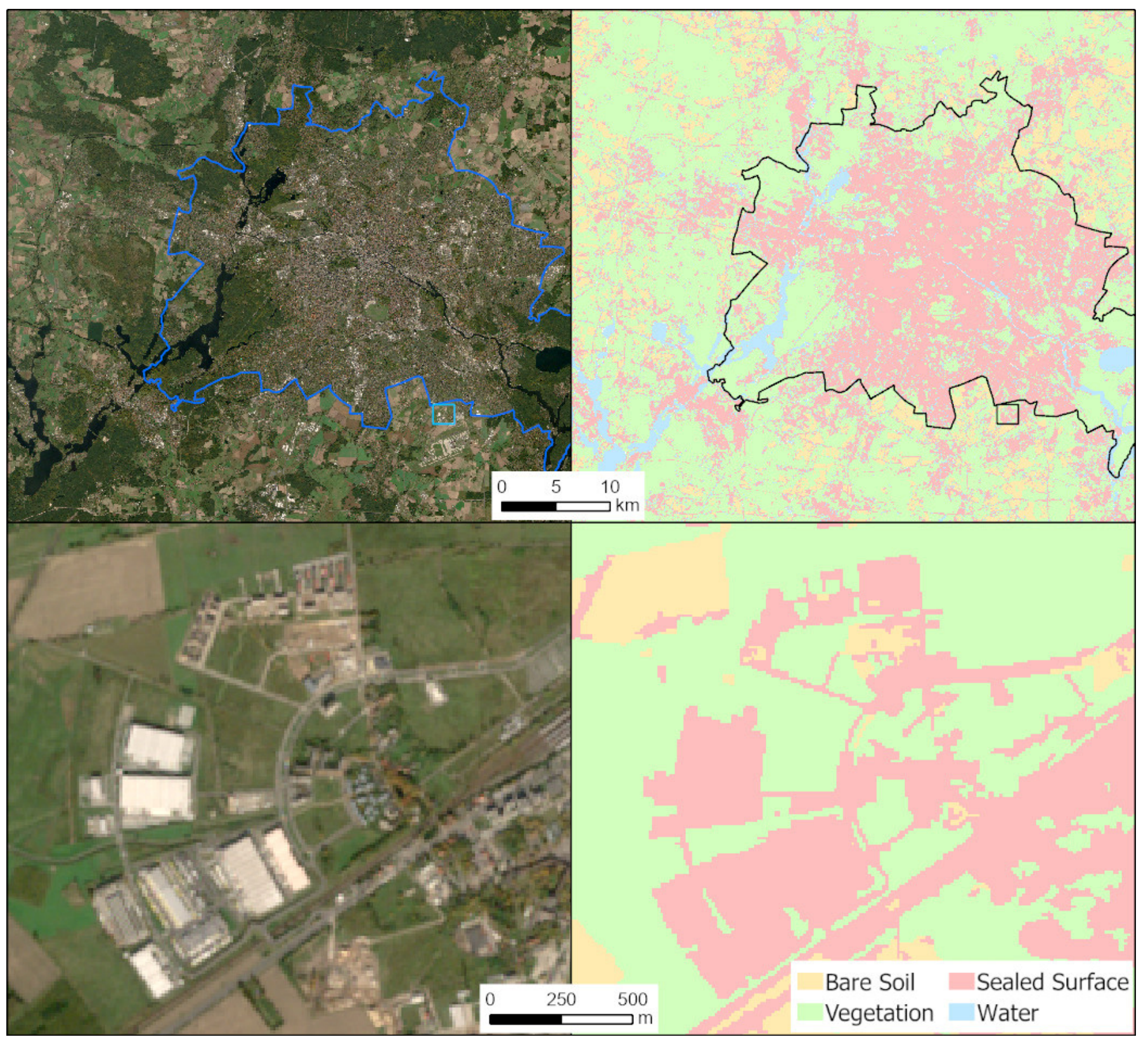

Figure 5. Sentinel-2 classification result of the 16 October 2017 for the complete study area (top) and in detail (below). Image source: Copernicus Sentinel data 2017 (accessed on 26 August 2020) [38].

From the classification results of all used scenes, area statistics are calculated and converted to diagrams (Figure 6). The differences of each land cover class over time can be seen for Berlin. The differences mainly relate to seasonal effects of green vegetation. It is challenging to identify increasing sealed surfaces directly from the areal statistics, as vegetation crown cover shields underlying sealed surfaces during certain time periods. 


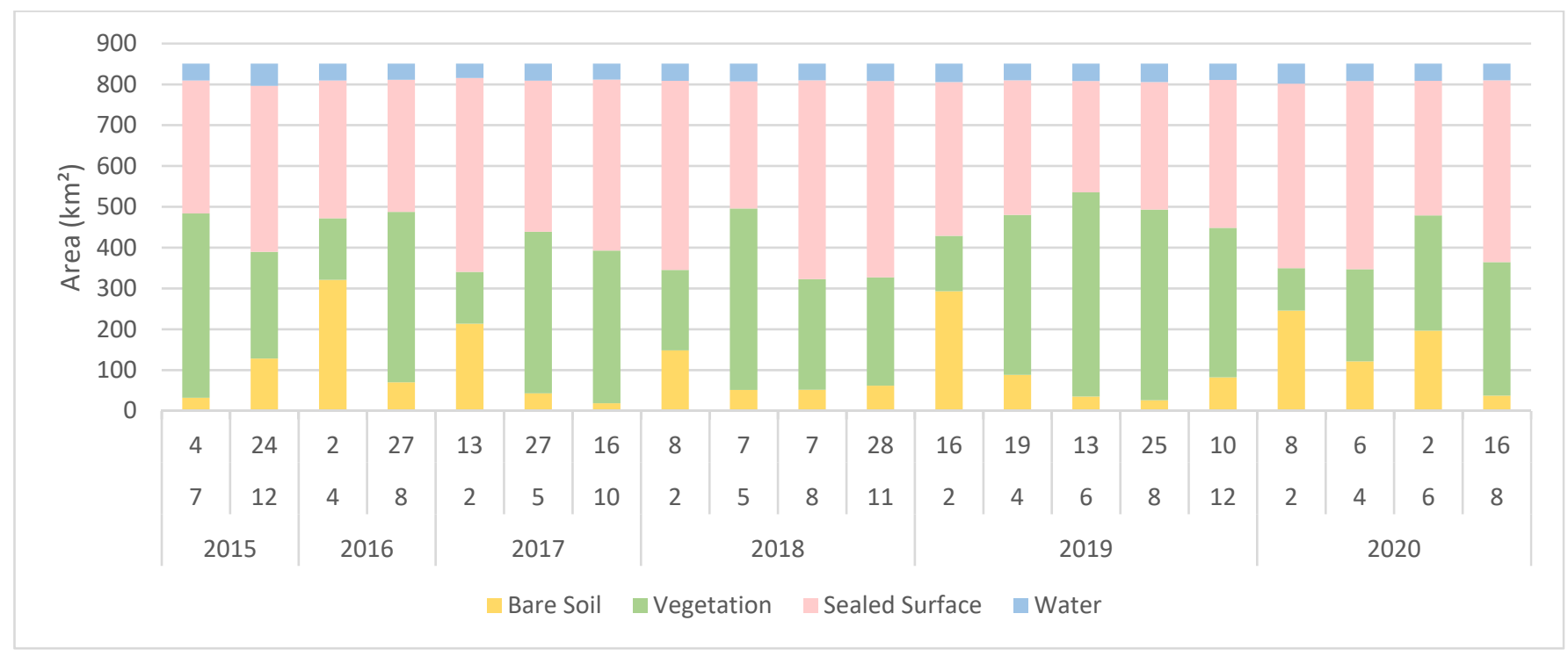

Figure 6. Classification results of the city of Berlin based on the Sentinel-2 images.

Table 8 compares the classification results to reference data. The average land cover statistics of the classification performed here (Sentinel-2 2015-2020 avg) differ significantly from the reference classification (DLR 2015-2017), especially in the case of Bare Soil. Bare Soil in the classification performed here appears mainly as low seasonal vegetation in the multi-temporally classified reference data set. This is because the reference was created with a different intention, which is reflected in the class descriptions. The multi-temporal classification allows one to integrate further knowledge of a second image that could possibly identify vegetation for one point in time. Then, this results in a type of seasonal vegetation. In the mono-temporal classification performed here this additional knowledge does not exist; the classifier can only rely on the reflected energy at one acquisition date.

Table 8. Land cover statistics (left and center) of the classifications in comparison to the Land Cover DE reference data set (DLR 2015-2017, right) [36].

\begin{tabular}{ccccccc}
\hline & \multicolumn{2}{c}{$\begin{array}{c}\text { Sentinel-2 2015-2020 } \\
\text { (Avg) }\end{array}$} & \multicolumn{2}{c}{ Sentinel-2 2017-10-16 } & \multicolumn{2}{c}{ DLR 2015-2017 } \\
& $\mathbf{k m}^{\mathbf{2}}$ & $\mathbf{\%}$ & $\mathbf{k m}^{\mathbf{2}}$ & $\mathbf{\%}$ & $\mathbf{k m}^{2}$ & $\mathbf{2}$ \\
\hline Bare Soil & 113 & 13 & 19 & 2 & 2 & 0 \\
Vegetation & 308 & 36 & 374 & 44 & 372 & 44 \\
Sealed & 387 & 45 & 419 & 49 & 429 & 50 \\
Surface & 43 & 5 & 39 & 5 & 47 & 6 \\
Water & 85 & 100 & 851 & 100 & 851 & 100 \\
\hline Sum & 851 & \multicolumn{3}{c}{ values are rounded } \\
\hline \multicolumn{7}{c}{}
\end{tabular}

In contrast to the averaged results of 2015-2020, a comparison of the classification result of 16 October 2017 with the reference data set reveals good fit (Figure 7). At this date the specified classes are classified mainly correctly. This proves that the classification approach itself is reliant, but a comparison with the reference could be misleading due to its multi-temporal character.

In addition to that, the identification of sealed surfaces is limited due to the size of the construction areas and the spatial resolution of the image data. This leads to the result that in many cases individual Sentinel-2 images are not suited to reliably identify construction activities in a city like Berlin. 


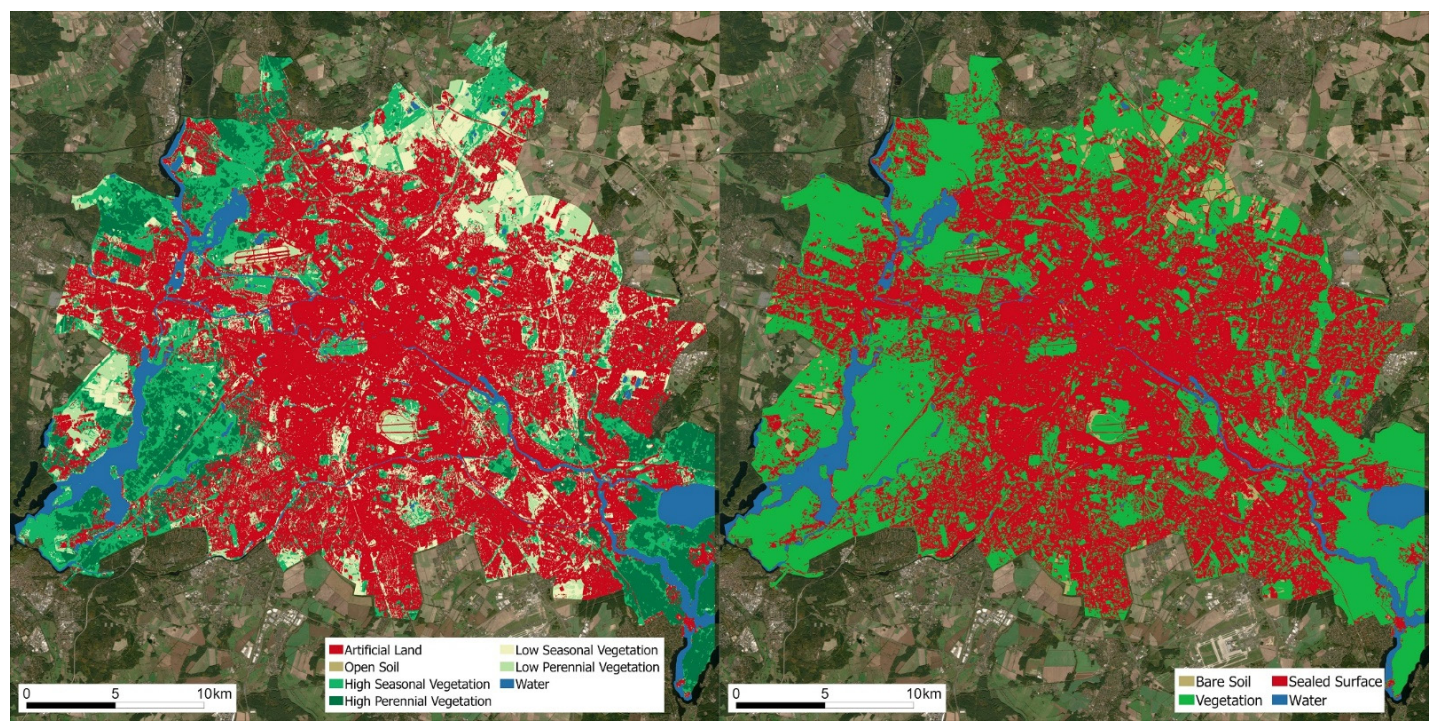

Figure 7. Comparison of the Sentinel-2 classification from 16 October 2017 (right) to the Land Cover DE reference dataset with original coloring (left, DLR 2020 [36]). The classes Bare Soil, Sealed Surface, and Water were colored to match the reference data. Background image: Sentinel-2 scene of 16 October 2017, image source: Copernicus Sentinel data 2017 (accessed on 26 August 2020) [38].

However, multi-temporal comparisons of subsequent image classification results indicate reasonable findings (Figure 8). The images clearly show the growing amount of sealed surface in the parcels that are already visible in the first image from 2015, up to a point where they are completely sealed in 2018. In addition, some of the construction sites stand out as bare soil and turn into sealing later. This could be verified with the Imperviousness Classified Change 2015-2018 reference data set, which is based on the same methodology (Copernicus) [35].

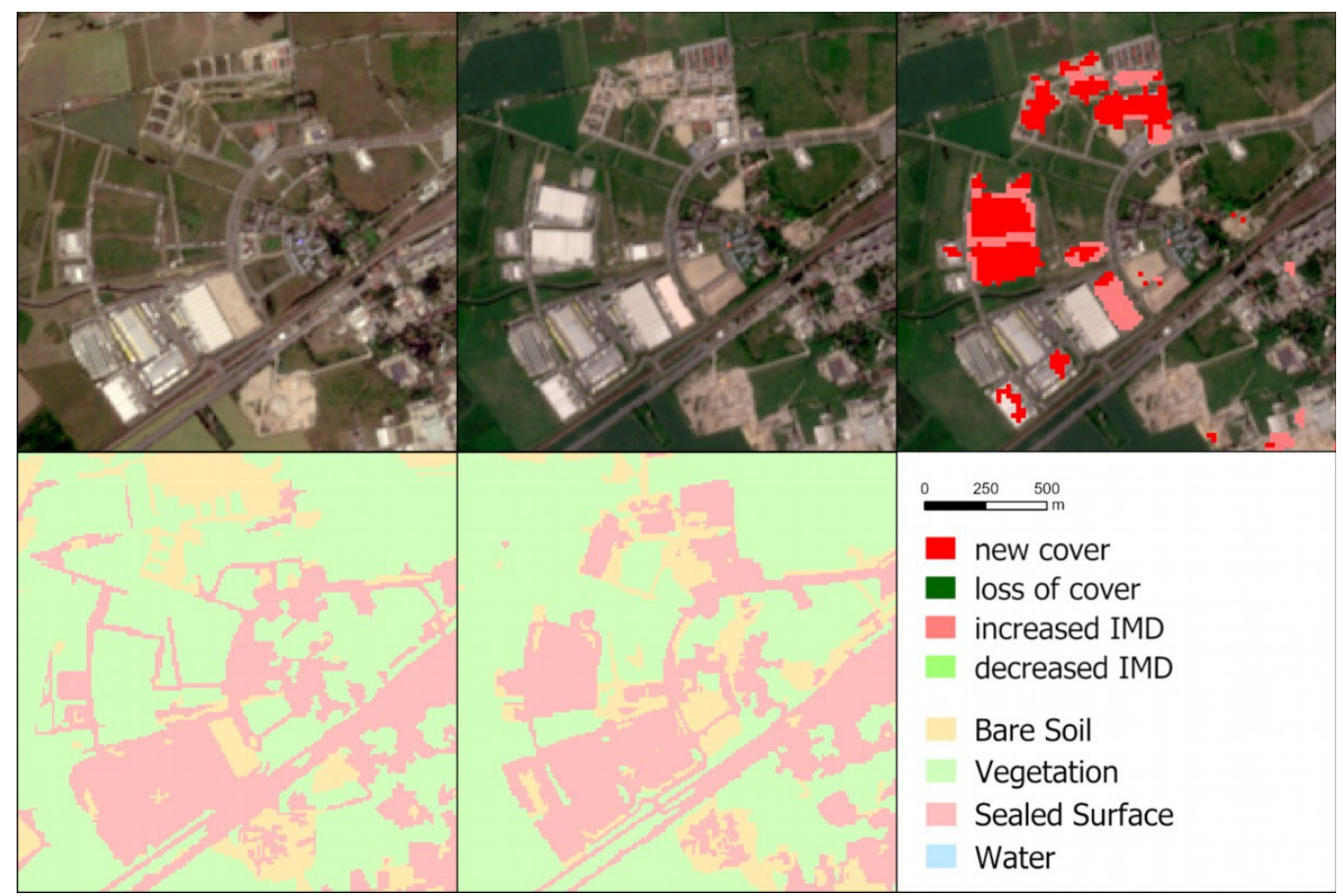

Figure 8. Identification of construction activities in the industrial area from Figure 5 in natural color Sentinel-2 scenes (top) and corresponding classification results (bottom) from 4 July 2015 (left) and 7 May 2018 (center). This is compared to the IMCC reference dataset (right). Image source: Copernicus Sentinel data 2018 (accessed on 26 August 2020) [38]. 


\subsection{Results of the WorldView Classification}

Compared with the Sentinel-2 results, the classification of the VHR WorldView scenes reveals much more differentiated results. Figure 9 exemplifies a classification result for the image of 29 April 2018 with many active construction areas.
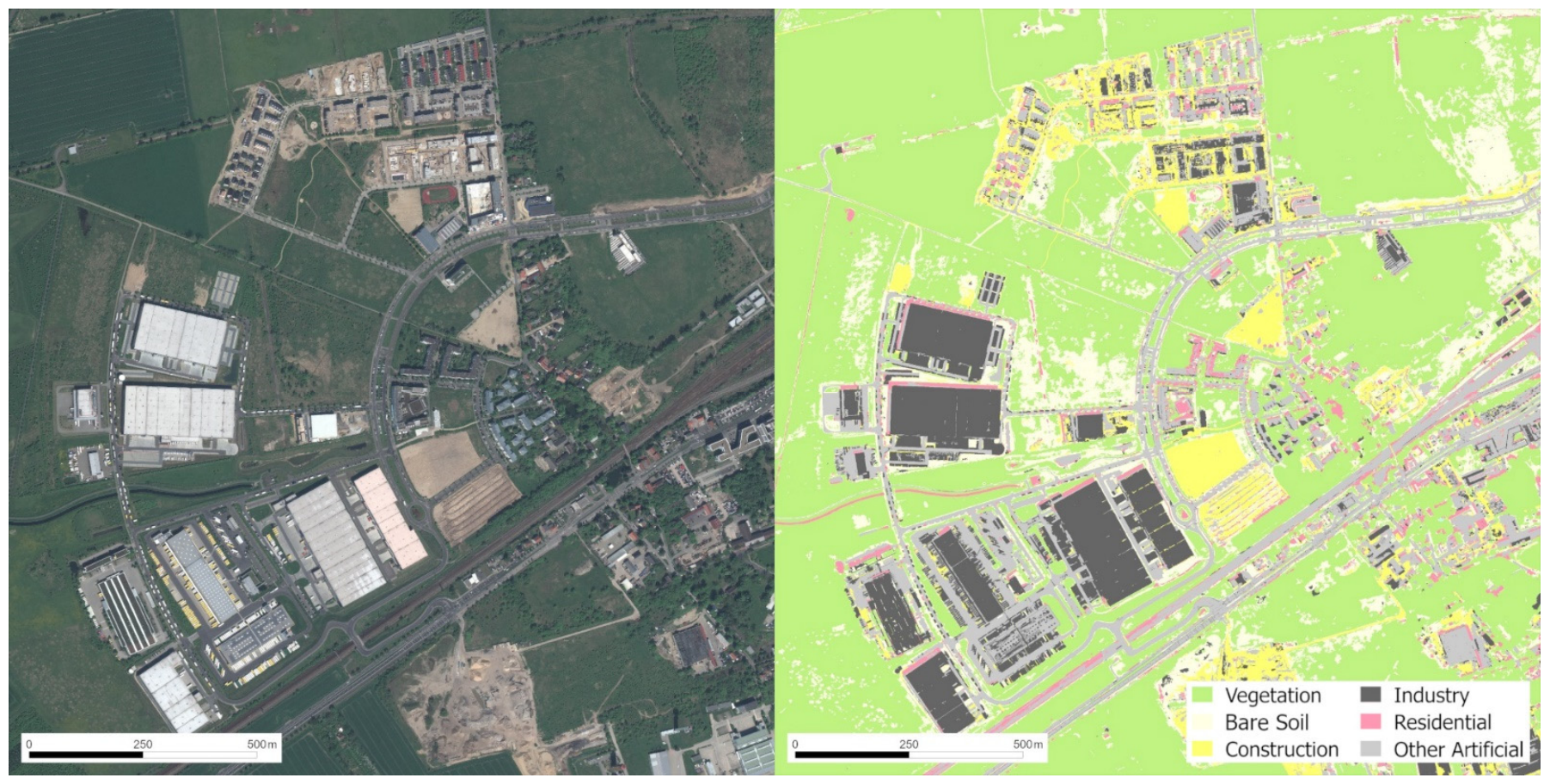

Figure 9. Detailed view of the WorldView classification result from the 29 April 2018. Image source: WorldView Image (C)2021, DigitalGlobe Inc., Westminster, CO, USA, a Maxar company [43].

These construction areas are clearly visible and can be discriminated from natural bare soils. However, spectral differences are dependent on other factors like the seasonal differences (e.g., sun angle, active/inactive construction sites) and varying degrees of soil moisture. Quantitative classification results for all VHR scenes are given for every class in Figure 10 and Table 9.

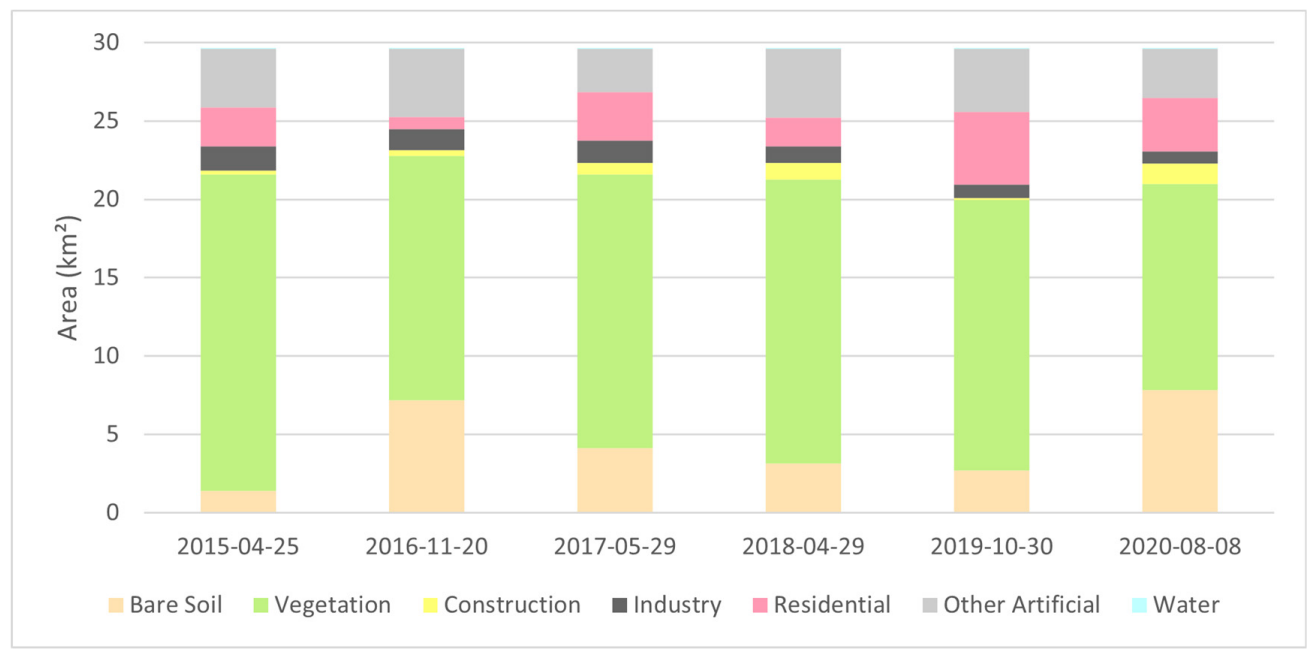

Figure 10. WorldView classification results of the study area. 
Table 9. Land cover statistics of the WorldView classifications.

\begin{tabular}{ccccccc}
\hline $\mathbf{k m}^{2}$ & $\mathbf{2 0 1 5 - 0 4 - 2 5}$ & $\mathbf{2 0 1 6 - 1 1 - 2 0}$ & $\mathbf{2 0 1 7 - 0 5 - 2 9}$ & $\mathbf{2 0 1 8 - 0 4 - 2 9}$ & $\mathbf{2 0 1 9 - 1 0 - 3 0}$ & $\mathbf{2 0 2 0 - 0 8 - 0 8}$ \\
\hline Bare Soil & 1.40 & 7.19 & 4.14 & 3.16 & 2.68 & 7.82 \\
Vegetation & 20.18 & 15.57 & 17.44 & 18.12 & 17.28 & 13.17 \\
Construction & 0.27 & 0.39 & 0.76 & 1.06 & 0.14 & 1.29 \\
Industry & 1.54 & 1.33 & 1.40 & 1.03 & 0.86 & 0.77 \\
Residential & 2.50 & 0.78 & 3.11 & 1.85 & 4.61 & 3.43 \\
Other & 3.74 & 4.37 & 2.78 & 4.38 & 4.06 & 3.14 \\
Artificial & 0.02 & 0.02 & 0.02 & 0.04 & 0.02 & 0.02 \\
Water & 29.64 & 29.64 & 29.64 & 29.64 & 29.64 & 29.64 \\
\hline Sum & & & & & &
\end{tabular}

Large commercial buildings as well as residential buildings can be reliably identified in all available VHR-scenes. However, some problems exist to separate residential buildings from other sealed surfaces. Misclassifications probably occur because of great spectral similarity of the materials.

The tree canopy cover effect occurs also in the VHR images during summer months and hides buildings underneath. This effect affects the land cover statistics during leave-on periods, compared to leave-off periods.

The mono-temporal classification results are then refined by GIS analysis techniques. One refinement approach is to search for characteristic classification patterns in known environments. For residential and industrial areas as well as construction areas, one analyzed eight cases each regarding their class composition. It is obvious that residential or industrial areas differ from construction areas (see Figure 11). A further discrimination between construction sites for residential or industrial buildings is not possible during the period of construction. In Figure 12 one can see the result for 29 April 2018.

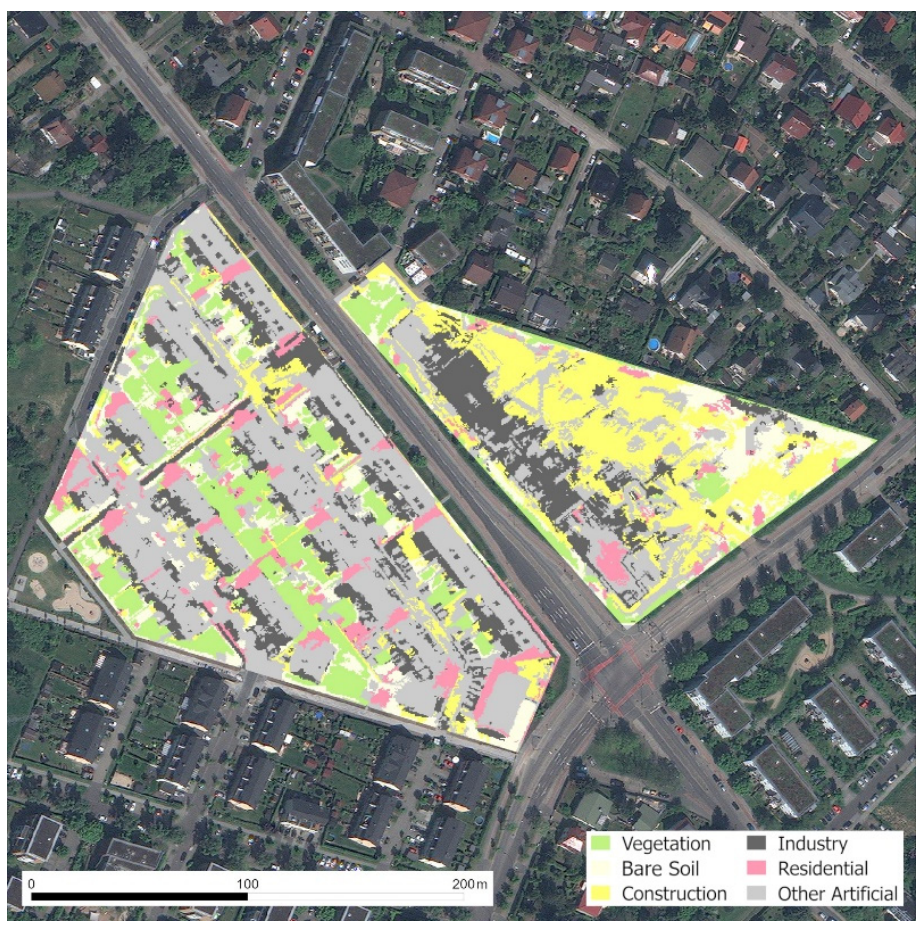

Figure 11. One residential area (left) and one construction site (right) for which the respective classification of the WV-3 scene from 29 April 2018 was extracted. Image source: WorldView Image (C2021, DigitalGlobe Inc., Westminster, CO, USA, a Maxar company [43]. 


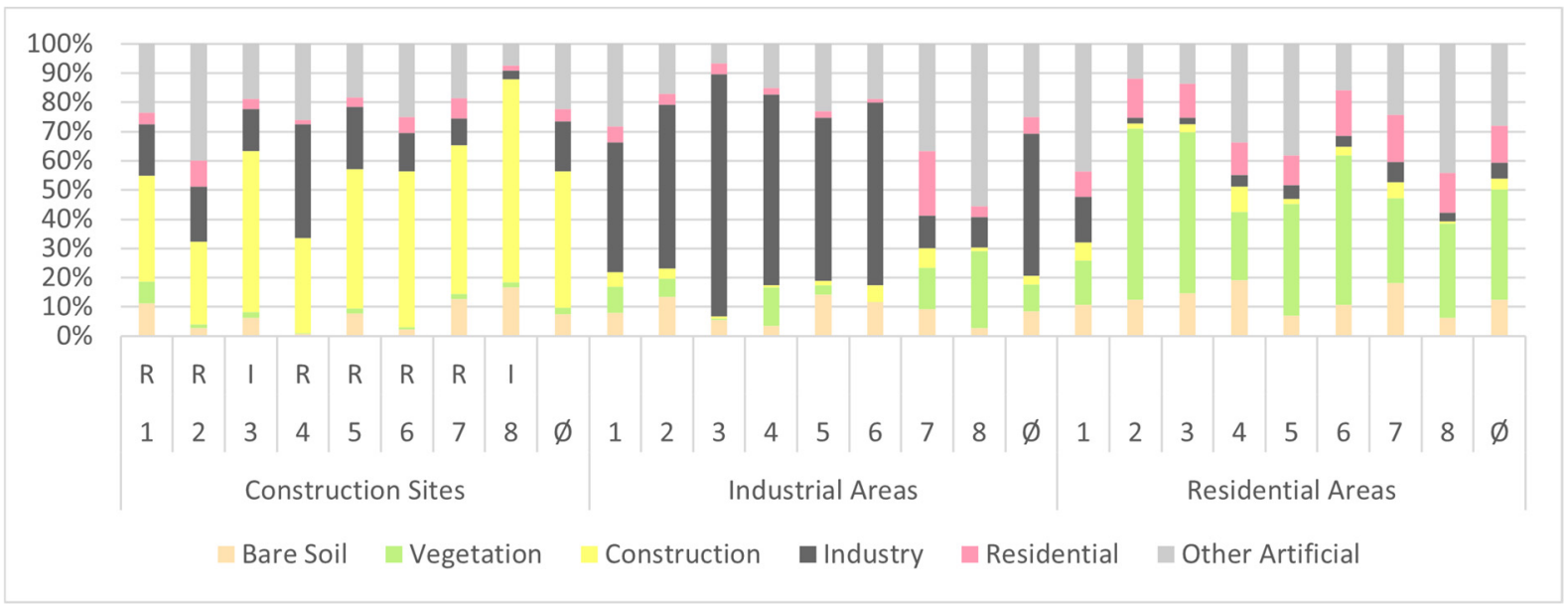

Figure 12. Land cover composition pattern of all extracted areas from Figure 11 (29 April 2018). R indicates construction sites for residential buildings, I indicates construction sites for industry buildings.

The multi-temporal approaches detect different stages of construction or even new houses directly. The results are slightly dependent on the season. It is easy to detect construction sites in vital vegetation conditions of spring and early summer. In contrast to that, winter scenes or dry-season scenes cause more misclassifications, possibly because bare soil and construction sites become spectrally more congruent. For this reason, different multi-temporal approaches are tested, as given in Table 7. For all three post-classification comparison approaches, individual thresholds (minimum size) are defined to accept the detected change to be significant. Approach A identifies basically new buildings and sealed surfaces of at least $50 \mathrm{~m}^{2}$ size without identifying a construction area (Figure 13). In Figure 14, areas larger than $20 \mathrm{~m}^{2}$ are shown that are (according to approach B) unsealed in the first year, classified as construction sites in the second year, and sealed in the third year. In addition to that, Figure 15 represents approach $C$ with areas larger than $20 \mathrm{~m}^{2}$ that are under construction in two consecutive images.

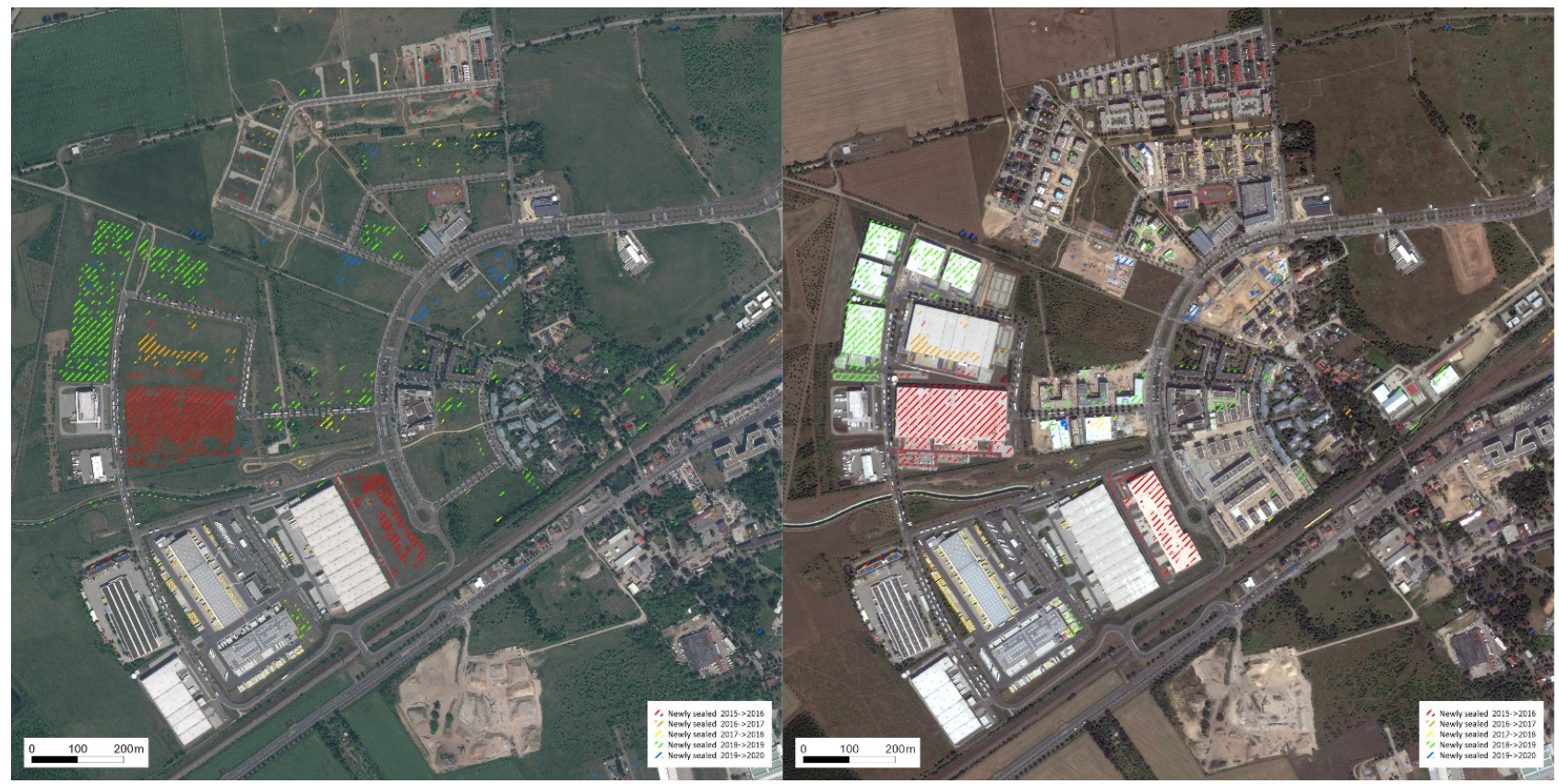

Figure 13. Multi-temporal post-classification result (approach A), displayed on two WorldView scenes (24 May 2015 (left) and 8 August 2020 (right)). One can identify areas that were unsealed in the first year and sealed in the second. Image source: WorldView Image @2021, DigitalGlobe Inc., Westminster, CO, USA, a Maxar company [43]. 


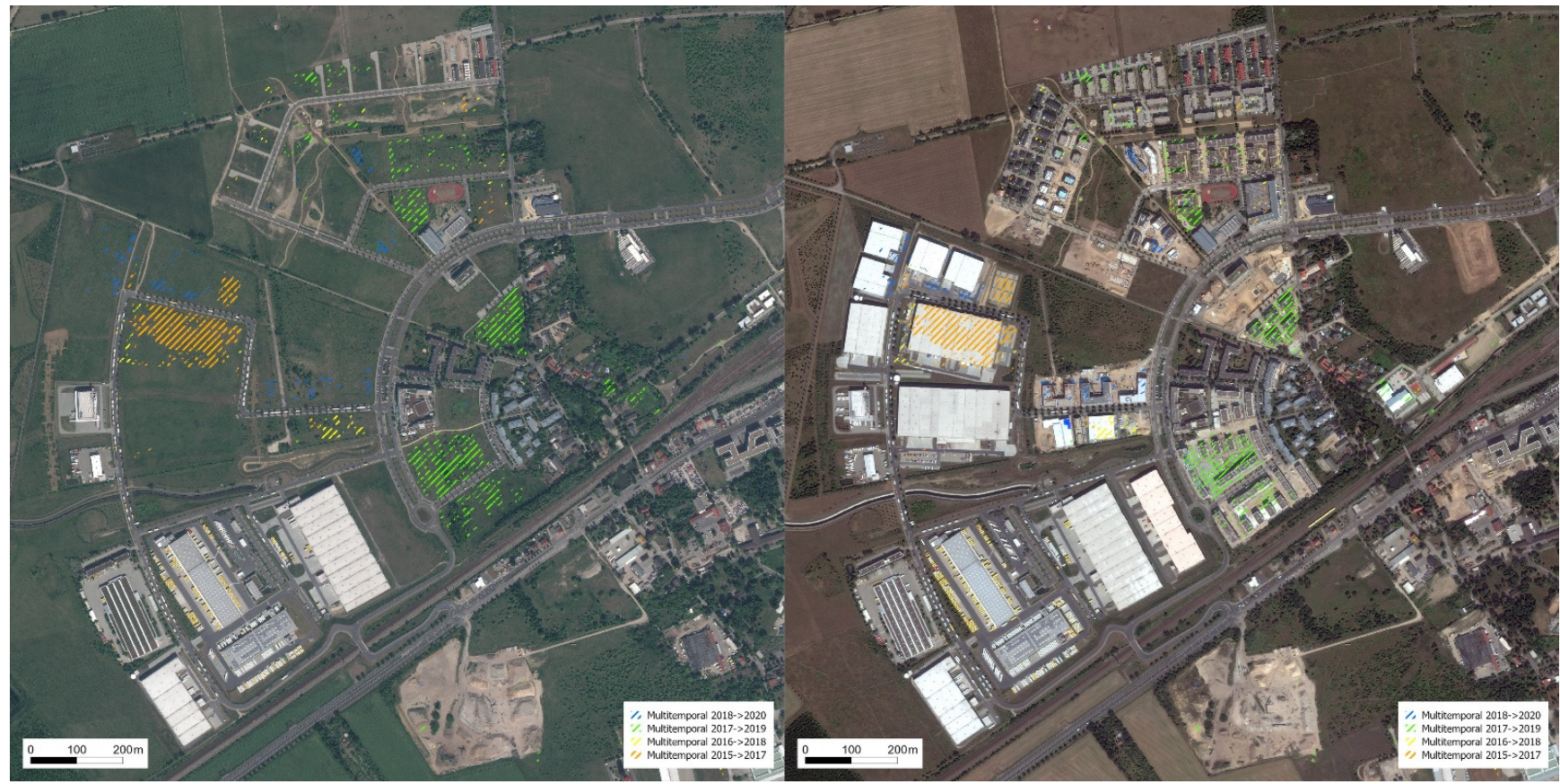

Figure 14. Multi-temporal post-classification result (approach B), displayed on two WorldView scenes (24 May 2015 (left) and 8 August 2020 (right)). One can identify areas that were not sealed in the first year of observation, were under construction in the second year, and ended up as buildings or sealed surfaces in the third year. Image source: WorldView Image @2021, DigitalGlobe Inc., Westminster, CO, USA, a Maxar company [43].

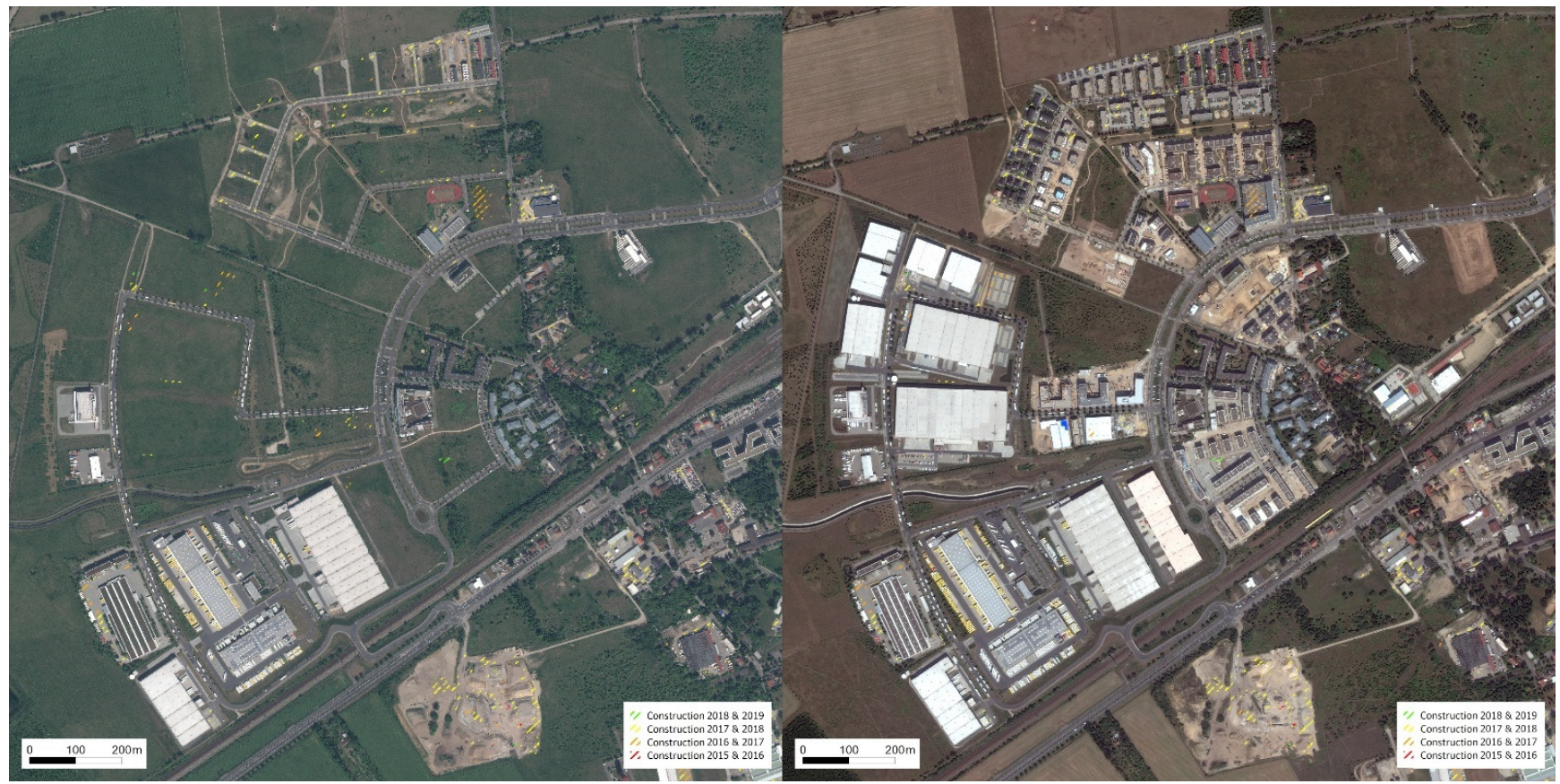

Figure 15. Multi-temporal post-classification result (approach C), displayed on two WorldView scenes (24 May 2015 (left) and 8 August 2020 (right)). One can identify areas that were under construction for two years. Image source: WorldView Image (02021, DigitalGlobe Inc., Westminster, CO, USA, a Maxar company [43].

The detected changes are then compared with the areal extent of new buildings and surrounding sealed areas. This reference is created very restrictively in the sense that only confident buildings and their sealed surrounding are considered for the comparison with the post-classification results. This is the basis to judge the accuracy of the determined 
construction area. Those that turned into buildings over a longer period of time are not considered until full completion. This means that only the smallest possible area is considered reliable and timely in the verification process. There is no other reference data set for construction areas available. This is due to the specific and ephemeral nature of construction areas. The verification results are listed in Table 10.

Table 10. Post-classification verification results.

\begin{tabular}{|c|c|c|c|c|}
\hline & Approach & Total & \multicolumn{2}{|c|}{ True Positive } \\
\hline & Mono-temporal Pattern 2015 & $266,821 \mathrm{~m}^{2}$ & $33,641 \mathrm{~m}^{2}$ & $12.6 \%$ \\
\hline & Mono-temporal Pattern 2016 & $389,695 \mathrm{~m}^{2}$ & $55,351 \mathrm{~m}^{2}$ & $14.2 \%$ \\
\hline & Mono-temporal Pattern 2017 & $757,578 \mathrm{~m}^{2}$ & $144,010 \mathrm{~m}^{2}$ & $19.0 \%$ \\
\hline & Mono-temporal Pattern 2018 & $1,061,411 \mathrm{~m}^{2}$ & $406,272 \mathrm{~m}^{2}$ & $38.2 \%$ \\
\hline & Mono-temporal Pattern 2019 & $141,134 \mathrm{~m}^{2}$ & $71,006 \mathrm{~m}^{2}$ & $50.3 \%$ \\
\hline \multirow{5}{*}{ A } & Newly sealed 2015-2016 & $57,566 \mathrm{~m}^{2}$ & $46,614 \mathrm{~m}^{2}$ & $80.9 \%$ \\
\hline & Newly sealed 2016-2017 & $98,167 \mathrm{~m}^{2}$ & $20,150 \mathrm{~m}^{2}$ & $20.5 \%$ \\
\hline & Newly sealed 2017-2018 & $30,230 \mathrm{~m}^{2}$ & $13,477 \mathrm{~m}^{2}$ & $44.5 \%$ \\
\hline & Newly sealed 2018-2019 & $84,150 \mathrm{~m}^{2}$ & $44,962 \mathrm{~m}^{2}$ & $53.4 \%$ \\
\hline & Newly sealed 2019-2020 & $105,099 \mathrm{~m}^{2}$ & $51,645 \mathrm{~m}^{2}$ & $49.1 \%$ \\
\hline \multirow{4}{*}{ B } & Multi-temporal 2015-2017 & $27,528 \mathrm{~m}^{2}$ & $26,821 \mathrm{~m}^{2}$ & $97.4 \%$ \\
\hline & Multi-temporal 2016-2018 & $49,107 \mathrm{~m}^{2}$ & $44,583 \mathrm{~m}^{2}$ & $90.7 \%$ \\
\hline & Multi-temporal 2017-2019 & $118,761 \mathrm{~m}^{2}$ & $112,293 \mathrm{~m}^{2}$ & $94.5 \%$ \\
\hline & Multi-temporal 2018-2020 & $11,994 \mathrm{~m}^{2}$ & $10,670 \mathrm{~m}^{2}$ & $88.9 \%$ \\
\hline \multirow{4}{*}{$\mathrm{C}$} & Biennial 2015 \& 2016 & $458 \mathrm{~m}^{2}$ & $77 \mathrm{~m}^{2}$ & $16.8 \%$ \\
\hline & Biennial 2016 \& 2017 & $10,083 \mathrm{~m}^{2}$ & $1,364 \mathrm{~m}^{2}$ & $13.5 \%$ \\
\hline & Biennial 2017 \& 2018 & $68,469 \mathrm{~m}^{2}$ & $28,340 \mathrm{~m}^{2}$ & $41.3 \%$ \\
\hline & Biennial 2018 \& 2019 & $791 \mathrm{~m}^{2}$ & $620 \mathrm{~m}^{2}$ & $78.3 \%$ \\
\hline
\end{tabular}

\subsection{Results of the Machinery Detection}

After the template matching is performed, the result for the different spatial resolutions with indicators called 'precision' and 'recall' can be evaluated. Precision is the relation of correctly identified vehicles (true positives) from all hits (correct and false ones) of the matching procedure.

$$
\text { precision }=\frac{\text { true positives }}{\text { true positives }+ \text { false positives }}
$$

Recall or 'hit rate' is the relation of correctly identified vehicles (true positives) compared with the total number of all vehicles (correct and missed ones).

$$
\text { recall }=\frac{\text { true positives }}{\text { true positives }+ \text { false negatives }}
$$

Generally, higher values are better results. The values for recall and precision should always be used together for a complete evaluation. This is due to the fact that a precision of $90 \%$ means that 9 out of 10 vehicles really exist. This indicator does not inform one about missed vehicles. In addition to that, a recall value of 100\% simply expresses that all available vehicles were identified. It does not inform one about vehicles that were counted but are not existent.

Figure 16 shows the results for the template matching for the different spatial resolutions with multiple templates and $80 \%$ correlation. 


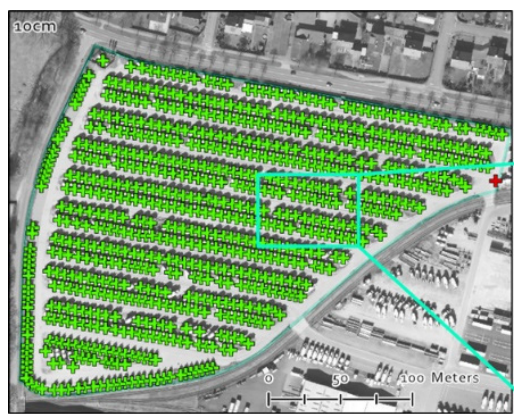

Template Matching $10 \mathrm{~cm}$

मै True Positives (727)

False Positives (1)
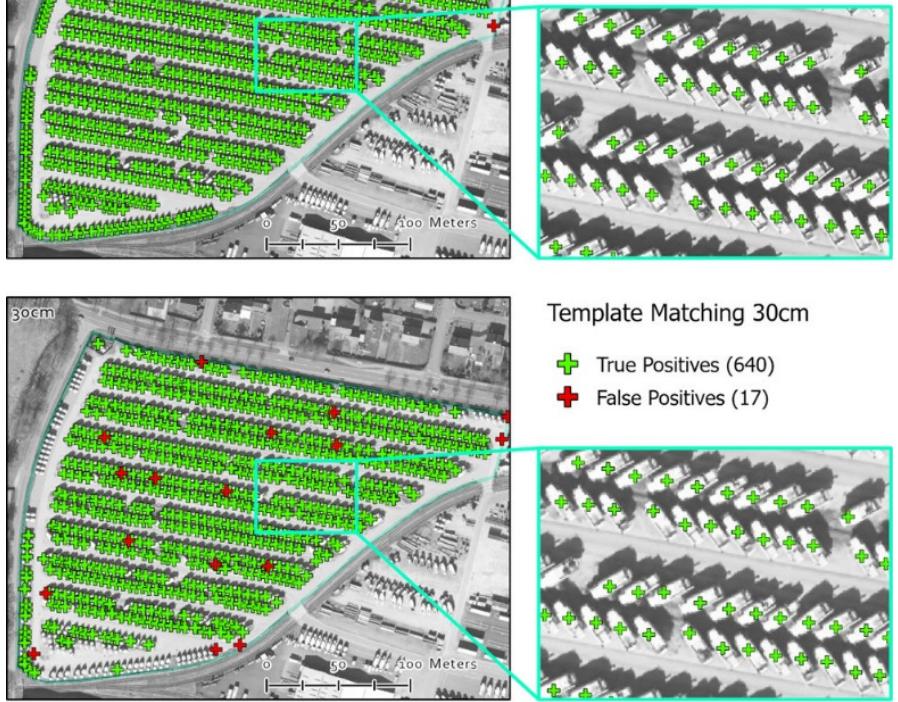

Template Matching $30 \mathrm{~cm}$

\{ True Positives (640)

t False Positives (17)
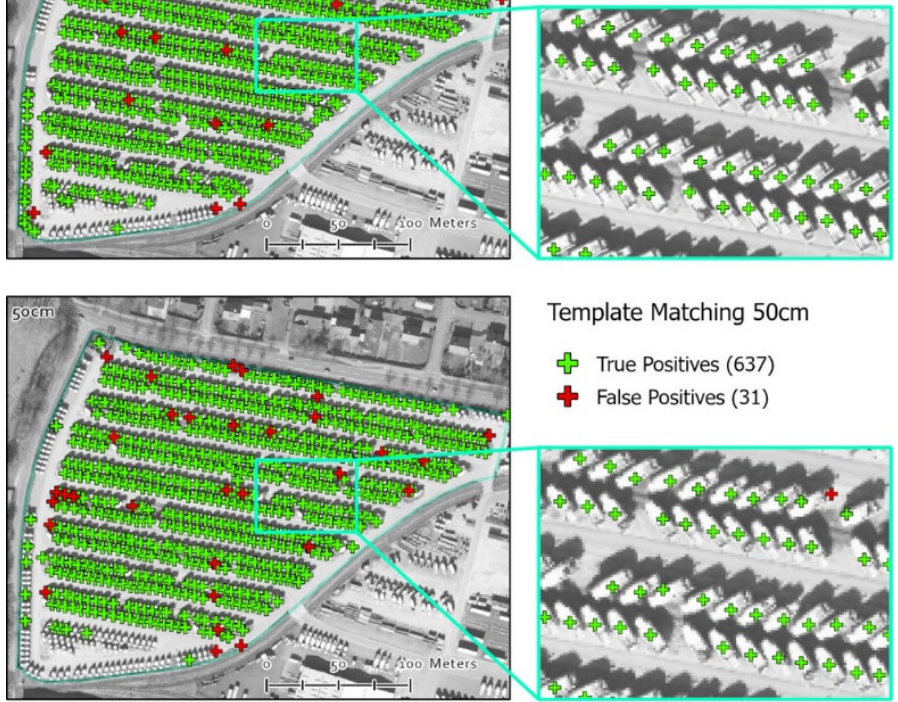

Template Matching $50 \mathrm{~cm}$

f5 True Positives (637)

False Positives (31)
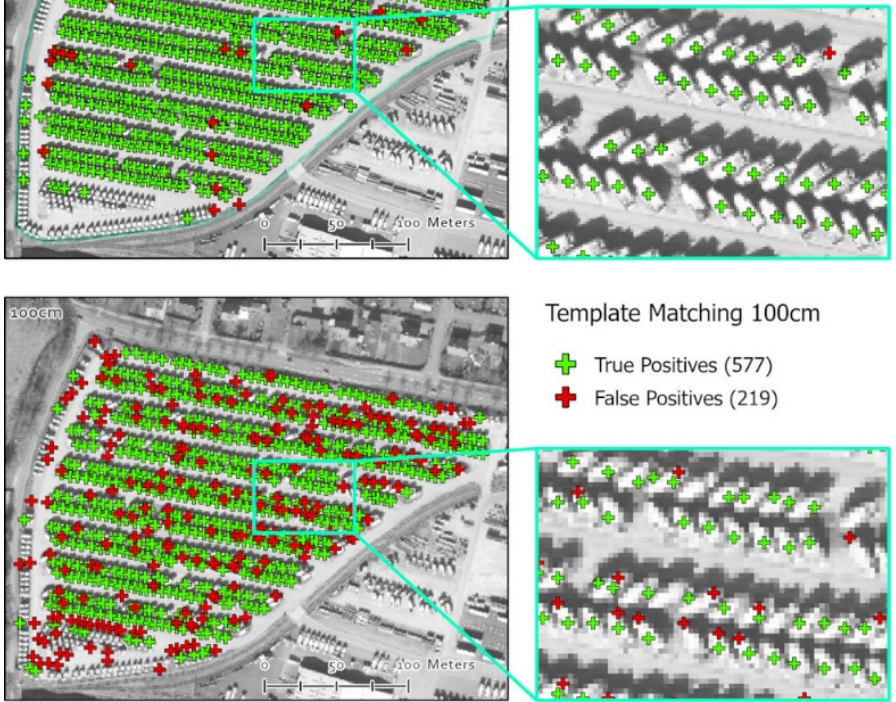

Template Matching $100 \mathrm{~cm}$

구 True Positives (577)

+ False Positives (219)

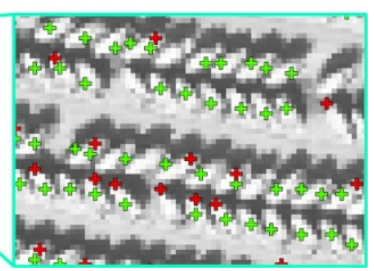

Figure 16. Template matching results comparing resolutions of 10, 30, 50 and $100 \mathrm{~cm}$. Orthophoto from 27 March 2017. Image source: Land NRW, http: / / www.govdata.de/dl-de/zero-2-0 (accessed on 5 June 2021) [42].

Table 11 additionally summarizes the results and confirms that both $30 \mathrm{~cm}$ and $50 \mathrm{~cm}$ spatial resolution provide reliable results. However, with coarser resolution the results slightly decline. In particular, small objects are characterized by less reliable results meaning higher amount of less true positives. The image with $100 \mathrm{~cm}$ spatial resolution reveals weaker results, which is due to the more difficult cognition of the vehicles' shape. 
Table 11. Results of the template matching for different resolutions.

\begin{tabular}{ccc}
\hline Resolution & Precision & Recall \\
\hline $10 \mathrm{~cm}$ & $99.9 \%$ & $97.7 \%$ \\
$30 \mathrm{~cm}$ & $97.4 \%$ & $86.0 \%$ \\
$50 \mathrm{~cm}$ & $95.4 \%$ & $85.6 \%$ \\
$100 \mathrm{~cm}$ & $71.3 \%$ & $75.3 \%$ \\
\hline
\end{tabular}

This feasibility study underlines that VHR satellite images like from the WorldView satellite family could be well suited for detection and identification of agricultural machinery in the examined size class. This could be used for future economic forecasts of this investment parameter.

\section{Discussion}

This study attempts to measure two economic variables directly by using satellite images: new buildings or construction areas and agricultural machinery. It is one of the few studies trying to use HR and VHR satellite data for an application in short-term economic forecasting. One advantage of satellite images is that it is possible to measure construction activities directly by identifying affected areas or objects. In contrast, current forecasting models use more indirect indicators such as building permits or the number of workers in the construction sector. A second advantage is that using satellite data allows the provision of regionally strongly differentiated information about construction activities.

Regarding the detection of construction activities, one can assume that Sentinel-2 images can be used to detect new buildings. However, the results were dependent on season. Confusion with bare soil as well as vegetation cover could influence the distinct detection. Regardless of the high temporal frequency, the spectral ambiguity of some land covers in mono-temporal classification cannot be overcome due to seasonal effects. Application of multi-temporal classification approaches could help to overcome this and lead to much more reliable results. However, for this specific application, multi-temporal classification is not effective, due to the fact that quick changes are to be mapped. The multi-temporal approach could cause delays as it would need at least one second cloud-free image with the respective later acquisition date.

VHR satellite images benefit from the very high spatial resolution and can be used to detect construction sites as well as new buildings. Post-classification change detection approaches support the identification and help to categorize these objects. However, even these images suffer from seasonal fluctuations and ambiguity of other land cover categories. Another drawback is the costs associated with commercial satellite images. In conjunction with the small area captured per image this could hinder a broad application, e.g., nationwide. Here, a strategy concentrating on a number of well selected proxy locations could help to overcome this bottleneck.

The initial mono-temporal classifications of both Sentinel-2 and WorldView scenes are intentionally kept simple to better reveal the influence of the geometric resolution. However, in particular the classification of VHR-data could benefit from additional features such as shape, size, or texture.

Concerning the detection of agricultural machinery, it could be demonstrated that VHR satellites like WorldView with a spatial resolution of 30 to $50 \mathrm{~cm}$ are well suited for an object extraction approach via template matching. For this economic indicator nationwide imagery is not needed, and instead one could concentrate on the known locations of the manufacturers.

This study concentrates on the feasibility and on the development of practical and quick approaches. In a next step, the usability as well as the reliability in economic models must be evaluated. It is therefore necessary to create a time series with an annual or preferably quarterly (or even monthly) frequency. In order to evaluate its information content for forecasting activity in the construction sector and selected industries, a period of several years is required. 
One should also do research on the robustness of the economic models against shortcomings of the image analysis results such as missing observations caused by clouds.

The increasing availability of new earth observation satellites with higher spatial resolution and higher temporal revisit rates will most likely be beneficial in supporting the data needs for quick and reliable forecasts.

Further research could also investigate weather independent RADAR images based on synthetic aperture Radar (SAR) to overcome the cloud cover problem of optical satellites.

\section{Conclusions}

The results of this study show that VHR satellite images are a new and unconventional source of information to be added to short-term economic forecasts. The information gained by machine learning techniques is up-to-date and cannot be delivered by other sources. The detection of construction areas from VHR satellite images is much more reliable than from HR satellite images. VHR satellite images with a ground resolution of $30-50 \mathrm{~cm}$ are able to identify agricultural machinery with high precision.

In its present stage the results are based on optical satellite images, which might suffer from cloud coverage that obscures the view of the Earth's surface and its objects, like buildings or agricultural machinery. Further research will have to overcome these limitations by integrating additional image sources. In addition to that, a higher degree of automation in image object identification could be beneficial for a routine application.

Author Contributions: Conceptualization, C.J. and T.S.; methodology, C.J., M.G., and F.M.M.-H.; image analysis and GIS processing, F.M.M.-H. and M.G.; writing-original draft preparation, C.J., F.M.M.-H., M.G., and T.S.; writing-review and editing, C.J., T.S., F.M.M.-H., and M.G.; visualization, F.M.M.-H. and M.G.; supervision, C.J.; project administration, C.J. and T.S.; funding acquisition, T.S. All authors have read and agreed to the published version of the manuscript.

Funding: This project is based on the project "Big Data in der makroökonomischen Analyse (Fachlos 3)" carried out on behalf of the German Federal Ministry for Economic Affairs and Energy.

Institutional Review Board Statement: Not applicable.

Informed Consent Statement: Not applicable.

Data Availability Statement: The data are not publicly available due to restrictions that apply to the availability of these data given by the funding agency.

Acknowledgments: The project cooperation and the discussions within the group of project members was highly appreciated.

Conflicts of Interest: The authors declare no conflict of interest.

\section{References}

1. Alaloul, W.; Musarat, M.; Rabbani, M.; Iqbal, Q.; Maqsoom, A.; Farooq, W. Construction Sector Contribution to Economic Stability: Malaysian GDP Distribution. Sustainability 2021, 13, 5012. [CrossRef]

2. Agnello, L.; Schuknecht, L. Booms and busts in housing markets: Determinants and implications. J. Hous. Econ. 2011, 20, 171-190. [CrossRef]

3. Lee, S.; Tidwell, A.; Jin, C. Residential Housing Market and Bank Stability: Focusing on OECD and Emerging Asian Countries. J. Real Estate Res. 2021, 43, 1-23. [CrossRef]

4. Carrasco-Gallego, J. Real Estate, Economic Stability and the New Macro-Financial Policies. Sustainability 2020, 13, 236. [CrossRef]

5. Donaldson, D.; Storeygard, A. The View from Above: Applications of Satellite Data in Economics. J. Econ. Perspect. 2016, 30, 171-198. [CrossRef]

6. Ademmer, M.; Beckmann, J.; Bode, E.; Boysen-Hogrefe, J.; Funke, M.; Hauber, P.; Heidland, T.; Hinz, J.; Jannsen, N.; Kooths, S.; et al. Big Data in der Makroökonomischen Analyse; Institut für Weltwirtschaft (IfW): Kiel, Germany, 2021; ISBN 978-3-89456-347-9. Available online: http:/ / hdl.handle.net/10419/232048 (accessed on 9 June 2021).

7. Blagov, B.; Goebel, M.; Goecke, H.; Grömling, M.; Jentsch, C.; Jürgens, C.; Matthes, J.; Meyer-Heß, M.F.; Müller, H.; Putfarken, H.; et al. Big Data in der Makroökonomischen Analyse. Fachlos 3: Machbarkeitsstudie: Prognose von Ausrüstungsinvestitionen, Bauinvestitionen, Exporten Mit Unkonventionellen Datenquellen und Methoden; RWI Projektberichte: Essen, Germany, 2021.

8. Henderson, J.V.; Storeygard, A.; Weil, D.N. Measuring Economic Growth from Outer Space. Am. Econ. Rev. 2012, 102, 994-1028. [CrossRef] [PubMed] 
9. Small, C.; Elvidge, C.D.; Balk, D.; Montgomery, M. Spatial scaling of stable night lights. Remote Sens. Environ. 2011, 115, 269-280. [CrossRef]

10. Nordhaus, W.; Chen, X. A sharper image? Estimates of the precision of nighttime lights as a proxy for economic statistics. J. Econ. Geogr. 2014, 15, 217-246. [CrossRef]

11. Addison, D.; Stewart, B. Nighttime Lights Revisited: The Use of Night Time Lights Data as a Proxy for Economic Variables. Available online: https:/ / openknowledge.worldbank.org/handle/10986/23460 (accessed on 16 June 2021).

12. Leßmann, C.; Seidel, A.; Steinkraus, A. Satellitendaten zur Schätzung von Regionaleinkommen-Das Beispiel Deutschland. ifo Dresd. Ber. 2015, 22, 35-42.

13. Fasial, K.; Shaker, A. The Use of Remote Sensing Technique to Predict Gross Domestic Product (GDP): An Analysis of Built-Up Index and GDP in Nine Major Cities in Canada. In Proceedings of the International Archives of the Photogrammetry, Remote Sensingand Spatial Information Sciences, Istanbul, Turkey, 29 September-2 October 2014; Volume XL-7, pp. 85-92.

14. SpaceKnow: Let's Talk about Satellite Artificial Intelligence. Available online: https://spaceknow.com/technology (accessed on 16 June 2021).

15. Schartner, C. Fernerkundung für Wirtschafts- und Sozialstatistik. In Proceedings of the Nationales Forum für Fernerkundung und Copernicus 2018, Berlin, Germany, 29 November 2018. Available online: https:/ /d-copernicus.de/fileadmin/Content/pdf/ Forum_2018/CopernicusForum2018_SessionD.3_Statistik_Schartner_Wirtschaftsstatistik.pdf (accessed on 29 November 2018).

16. Riao, D.; Zhu, X.; Tong, Z.; Zhang, J.; Wang, Y. Study on Land Use/Cover Change and Ecosystem Services in Harbin, China. Sustainability 2020, 12, 6076. [CrossRef]

17. Wang, Y.; Zhao, X.; Zuo, L.; Zhang, Z.; Wang, X.; Yi, L.; Liu, F.; Xu, J. Spatial Differentiation of Land Use and Landscape Pattern Changes in the Beijing-Tianjin-Hebei Area. Sustainability 2020, 12, 3040. [CrossRef]

18. Myint, S.W.; Gober, P.; Brazel, A.; Grossman-Clarke, S.; Weng, Q. Per-pixel vs. object-based classification of urban land cover extraction using high spatial resolution imagery. Remote Sens. Environ. 2011, 115, 1145-1161. [CrossRef]

19. Blaschke, T.; Lang, S.; Hay, G. Object-Based Image Analysis: Spatial Concepts for Knowledge-Driven Remote Sensing Applications; Springer: Berlin/Heidelberg, Germany, 2008.

20. Mao, W.; Lu, D.; Hou, L.; Liu, X.; Yue, W. Comparison of Machine-Learning Methods for Urban Land-Use Mapping in Hangzhou City, China. Remote Sens. 2020, 12, 2817. [CrossRef]

21. Xi, Y.; Thinh, N.X.; Li, C. Preliminary comparative assessment of various spectral indices for built-up land derived from Landsat-8 OLI and Sentinel-2A MSI imageries. Eur. J. Remote Sens. 2019, 52, 240-252. [CrossRef]

22. Pesaresi, M.; Corbane, C.; Julea, A.; Florczyk, A.J.; Syrris, V.; Soille, P. Assessment of the Added-Value of Sentinel-2 for Detecting Built-up Areas. Remote Sens. 2016, 8, 299. [CrossRef]

23. Radke, R.J.; Andra, S.; Al-Kofahi, O.; Roysam, B. Image change detection algorithms: A systematic survey. IEEE Trans. Image Process. 2005, 14, 294-307. [CrossRef]

24. Olteanu-Raimond, A.-M.; See, L.; Schultz, M.; Foody, G.; Riffler, M.; Gasber, T.; Jolivet, L.; Le Bris, A.; Meneroux, Y.; Liu, L.; et al. Use of Automated Change Detection and VGI Sources for Identifying and Validating Urban Land Use Change. Remote Sens. 2020, 12, 1186. [CrossRef]

25. Henits, L.; Jürgens, C.; Mucsi, L. Seasonal multitemporal land-cover classification and change detection analysis of Bochum, Germany, using multitemporal Landsat TM data. Int. J. Remot. Sens. 2016, 37, 3439-3454. [CrossRef]

26. Juergens, C.; Meyer-Heß, M. Identification of Construction Areas from VHR-Satellite Images for Macroeconomic Forecasts. Remote Sens. 2021, 13, 2618. [CrossRef]

27. Jasvilis, G.; Weise, C.; Zenger-Landolt, B. Finding Complex Patterns Using Template Matching. Available online: https: // proceedings.utwente.nl/402/ (accessed on 16 September 2016).

28. Rosenski, N.; Schartner, C. Remote Sensing Data for Better Statistics. In Proceedings of the 16th Conference of the International Association of Official Statisticians (IAOS), OECD Headquarters, Paris, France, 19-21 September 2018. Available online: https: / /www.makswell.eu/event_attachments/19_21-9-2018/iaos-oecd2018_rosenski_schartner.pdf (accessed on 12 February 2020).

29. Zambanini, S.; Loghin, A.-M.; Pfeifer, N.; Soley, E.M.; Sablatnig, R. Detection of Parking Cars in Stereo Satellite Images. Remote Sens. 2020, 12, 2170. [CrossRef]

30. Tang, T.; Zhou, S.; Deng, Z.; Zou, H.; Lei, L. Vehicle Detection in Aerial Images Based on Region Convolutional Neural Networks and Hard Negative Example Mining. Sensors 2017, 17, 336. [CrossRef] [PubMed]

31. Ng, S.T.; Fan, R.Y.; Wong, J.M. An econometric model for forecasting private construction investment in Hong Kong. Constr. Manag. Econ. 2011, 29, 519-534. [CrossRef]

32. Demers, F. Modelling and Forecasting Housing Investment: The Case of Canada. Available online: https://www.bankofcanada. ca/2005/12/working-paper-2005-41/ (accessed on 12 February 2020).

33. Lunsford, K.G. Forecasting residential investment in the United States. Int. J. Forecast. 2015, 31, 276-285. [CrossRef]

34. Aye, G.C.; Miller, S.M.; Gupta, R.; Balcilar, M. Forecasting US real private residential fixed investment using a large number of predictors. Empir. Econ. 2016, 51, 1557-1580. [CrossRef]

35. Copernicus. Imperviousness Classified Change 2015-2018. Available online: https://land.copernicus.eu/pan-european/highresolution-layers/imperviousness / change-maps /2015-2018/imperviousness-classified-change-2015-2018?tab=metadata (accessed on 18 March 2021). 
36. DLR (Deutsches Zentrum für Luft- und Raumfahrt). Land Cover DE-Sentinel-2-Germany. 2015. Available online: https: / / geoservice.dlr.de/data-assets/1ccmlap3mn39.html (accessed on 16 June 2021).

37. Weigand, M.; Staab, J.; Wurm, M.; Taubenböck, J. Spatial and semantic effects of LUCAS samples on fully automated land use/land cover classification in high-resolution Sentinel-2 data. Int. J. Appl. Earth Obs. Geoinf. 2020, 88, 102065. [CrossRef]

38. Copernicus Sentinel data 2015-2020. Available online: https://scihub.copernicus.eu/dhus/\#/home (accessed on 26 August 2020).

39. GeoBasis-DE/BKG 2021. Available online: https://sgx.geodatenzentrum.de/wms_dtk250 (accessed on 5 June 2021).

40. Jungnickl, C.; Bill, R. Abschätzung des Versiegelungsgrades mit Sentinel-2-Daten durch Anwendung von Bebauungsindizes. In Flächennutzungsmonitoring IX: Nachhaltigkeit der Siedlungs- und Verkehrsentwicklung? Meinel, G., Schumacher, U., Schwarz, S., Richter, B., Eds.; Rhombos-Verlag: Berlin, Germany, 2017; ISBN 978-3-944101-73-6.

41. Osgouei, P.E.; Kaya, S.; Sertel, E.; Alganci, U. Separating Built-Up Areas from Bare Land in Mediterranean Cities Using Sentinel-2A Imagery. Remote Sens. 2019, 11, 345. [CrossRef]

42. Land NRW. Available online: https:/ /www.opengeodata.nrw.de/produkte/geobasis/lbi/dop/dop_jp2_f10/ (accessed on 5 June 2021)

43. A Maxar Company. WorldView Image (C2021; DigitalGlobe Inc.: Westminster, CO, USA, 2021. 